\title{
Factors associated with uptake of cervical cancer screening services among female health workers in level 4 health facilities in Kisumu County, Kenya
}

\author{
Judy Ntabo', Dr. Daniel Mokaya², Caroline Musita ${ }^{2}$ \\ ${ }^{1}$ Student, College of Health Sciences, Jomo Kenyatta University of Agriculture and Technology, Kenya \\ ${ }^{2}$ Lecturer, College of Health Sciences, Jomo Kenyatta University of Agriculture and Technology, Kenya
}

DOI: 10.29322/IJSRP.11.08.2021.p11639

http://dx.doi.org/10.29322/IJSRP.11.08.2021.p11639

\begin{abstract}
Cervical cancer remains a public health concern, despite availability of National policy guidelines in early detection of the disease, and prompt initiation on treatment. Screening through Pap smear test or visual inspection are the primary methods recommended for use by Ministry of Health. In Kisumu County the high HIV prevalence, coupled with cervical cancer disease threatens better female population outcomes in the region. Currently, the uptake of cervical cancer screening in female health workers in Kisumu County remains unknown. This study set out to determine the factors associated with uptake of cervical cancer screening services among female health workers in level 4 health facilities within Kisumu County. Specifically, to determine the proportion of female health workers who have undergone cervical cancer screening; to establish the knowledge of cervical cancer and screening among female health workers; to assess the attitude of female health workers towards screening; and to identify the barriers to uptake of cervical cancer screening by female health workers. This was a descriptive cross-sectional study, employing both quantitative and qualitative approaches, conducted in 4 health facilities in Kisumu County. A sample size of 191 for quantitative and 25 for qualitative participants were recruited. These were
\end{abstract} distributed across the facilities using a proportionate allocation approach. Systematic random sampling was utilized at each facility to identify the participants from the human resource log, while purposive sampling was used to identify FGD participants. Descriptive analysis was done on participant's demographics, while inferential statistics using chi square test of association was done on participant's knowledge, attitude and barriers to cervical cancer screening. Data from FGD was analyzed using Atlas.ti. V.6.0.15 qualitative data management system. The study determined that $58.3 \%$ of female health workers had been screened for cervical cancer. Individuals between age 25-32 were similarly the most screened with a significant statistical association of age with screening uptake at chi sq. test of 2.151 at $\mathrm{p}=$ value of 0.001 at $95 \%$ CI. Seventy-four percent of the married participants had been screened. The study also established that knowledge of risk factors such as HIV infection, multiple sexual partners and HPV infection; prevention measures and symptoms, were significantly associated with uptake. Sixty-one percent of the participants who knew the risk factors had been screened, this was echoed by FGD participants as well. Experiencing symptoms had a chi sq. test value of 1.922 and a $p=$ value of 0.001 at 0.05 margin of error. The notable barrier to screening identified by the study was fear of the screening outcome and access to screening services. Results from all FGDs also showed that the participants had not screened for cervical cancer due to the fear of screening result. Those who sought screening did so since they were experiencing symptoms such as heavy vaginal bleeding and persistent lower abdominal pain. This study concluded that age, marital status, knowledge of cervical cancer and cervical cancer screening, fear of the screening outcome significantly influenced uptake. The findings of this study will help Ministry of Health develop policies that ensure health care workers undergo vital medical interventions such as cervical cancer screening regularly. Further, facilities of level 4 status should have medical experts who have skills to undertake cervical cancer screening. The study recommends further qualitative surveys in other levels of health facilities to help unearth female health workers reluctance to undergo cervical cancer screening.

\section{BACKGROUND INFORMATION}

$\mathrm{C}$ ervical cancer is the second most common cancer among women worldwide and is the leading cause of death among women of reproductive age. Globally, 266,000 women $(50.4 \%$ of cases) die of cervical cancer annually. The World Health Organization (WHO) highlights that majority of these deaths can be prevented through universal access to comprehensive cervical cancer screening, prevention and control programs targeting women at risk, and use of the Human Papilloma Virus (HPV) vaccine (WHO, 2014). Treatment for pre-cancerous lesions would also prevent deaths (Ibid).

The burden of cervical cancer on its victims and families is overwhelming; this is because a lot of people seem to be poorly aware and indifferent to this disease exacerbated by the silent nature of the disease early on (Asuzu et al, 2012). In the year 2008, 529,409 cases occurred globally and about 274,883 women (52\% of cases) died of cervical cancer in that year (MOH, 2013). In 2012, 528,000 new cases of cervical cancer were diagnosed worldwide; a large majority (85\%) occurred in less developed countries.

During the same year 266,000 (50.4\%) women died of cervical cancer; almost 9 out of every 10 of these or 231,000 lived and died in low to middle income countries. This is comparable to 35,000 or just 1 out of 10 of these women lived and died in high 
income countries. The main reason for this disparity is the relative lack of effective preventive, early detection and treatment programs in low and middle income countries (WHO, 2014).

The burden of cervical cancer in terms of mortality is quite low in developed countries of the world $(13.2 \%)$ compared to that of developing countries $(86.8 \%)$. This is associated with increased use of the Pap smear and other screening tests. While the incidence is decreasing in the former, it is on the increase in the latter. This is a source of great concern considering the fact that cervical cancer is preventable and curable at low cost with currently available methods.

Sub-Saharan Africa (SSA) region has the highest incidence of cervical cancer in the world with concomitant high mortality affecting women at their prime (Ntekim, 2012). According to the American Cancer Society's (ACS), estimates for cervical cancer in the United States for 2017, about 12820 new cases of invasive cervical cancer were diagnosed and about 4210 women would die from the same (ACS, 2017).

Over the last 30 years, cervical cancer incidence and mortality rates have fallen in countries where social and economic status has improved and this has been largely attributed to implementation of secondary prevention efforts which include effective screening, early diagnosis and treatment for pre-cancer and early cancer (WHO, 2014).

In Kenya, cancer is the third highest cause of morbidity and mortality (7\% of deaths per year) after infectious and cardiovascular diseases. It is estimated that there are 39,000 new cases of cancer each year in the country with more than 27,000 deaths per year of which, $60 \%$ of Kenyans affected by cancer are less than 70 years old (KCNS, 2017)..

According to Barrionuevo et al (2016) Kenya has a population of 13.4 million women aged above 15 years who are at risk of developing cervical cancer. Data from hospital based registries in Kenya in the 10 years period (1981-1990) indicated that cancer of the cervix accounted for $8-20 \%$ of all cancer cases and $70-80 \%$ of all genital tract cancer cases. The incidence of cervical cancer in Kenya is estimated to be 4802 women per year with annual number of deaths estimated at 2451 women $(51 \%)$ (Ibid).

This is in line with a projection cited by Ndirangu et al (2013) who stated that "In the absence of accelerated intervention for screening, detection and early treatment, the incidence of cervical cancer is projected to rise to 4,261 resulting in 2,955 deaths in 2025". The crude incidence rate of cervical cancer is 22.4 per 100,000 populations. Fifty percent of the women diagnosed with cervical cancer die of the same in Kenya (Barrionuevo et al., 2016).

Although screening facilities are available, the incidence and mortality for cervical cancer remains very high as many women present to the health facility while in the late stage (Hoque and Hoque, 2008). According to the Kenya Demographic Health Survey (KNBS, 2014) $75 \%$ of women aged $15-49$ years have heard of cervical cancer, $14 \%$ have undertaken cervical cancer exam and amongst those who have undertaken the exam, $62 \%$ had a pap smear while $32 \%$ had a visual inspection. There is no data about this relating to female health workers alone in the country to my knowledge.

In Kisumu County, the uptake of cervical cancer screening is equally low. The county has 326009 females aged 15 to 49
$(58 \%)$. For instance, at Jaramogi Oginga Odinga Teaching and Referral Hospital (JOOTRH) on average, 3 women are screened daily yet the facility is a referral hospital that serves more than 100 districts and sub districts in more than 10 counties in Western Kenya region. Unpublished report from JOOTRH indicates that 1633 women were screened in 2016 of whom $206(12.6 \%)$ had a positive cervical cancer screening result. However the records do not show the proportions of heath service providers who participated. These numbers are low given the implication of late diagnosis and the advantages of early detection via screening.

A study conducted at JOOTRH found out that among 424 women who were interviewed, $17.5 \%$ reported going for cervical cancer screening indicating that the uptake is still low compared to the national target of $75 \%$ by the year 2009 (Morema et al., 2014). This study aimed to determine the factors associated with uptake of cervical cancer screening among female health workers who supposedly have adequate knowledge on this area and play a key role in promoting the uptake of this important service to the community at large. Moreover, they are deemed to be custodians of this service' in addition to the community considering health workers as models seeking their advice on many health matters. Health care workers attitudes and actions may be predictors of societal health behavior hence elucidating these is a worthwhile endeavor.

\subsection{Statement of the problem}

Cervical cancer remain the second most important malignancy among women aged 15-69 years in Kenya after breast cancer. It is also the leading cause of morbidity and mortality to thousands of women. The crude incidence rate per 100,000 per year is 22.4 (Barrionuevo et al., 2016). The socio-economic impact of cervical cancer on the patient and other family members is considerable and can have negative consequences on treatment and compliance. The impact include work interruptions, reduced hours in work and loss of family income and savings. Infertility is also another consequence of cervical cancer. Women who have advanced or invasive cervical cancer complication characterized by the inability to become pregnant as one of the most common treatments for cervical cancer is hysterectomy.

The WHO recommend five yearly cervical cancer screening for HIV negative women and annual screening for HIV positive women, especially among the reproductive age group. This recommendation has since been adopted by Kenya $\mathrm{MOH}$. Despite this, voluntary uptake of regular cervical cancer in Kenya that has a female population of 13.4 million women (as of December 2016) is still low at 3.2\%. Current estimates indicate that every year in Kenya, 4802 new cases of cervical cancer are reported and 2451 deaths occur from the disease (WHO, 2014). These deaths would be preventable if the female population appreciates the benefits of early detection and prompt treatment.

Despite the high level of knowledge and better access to the service, documented data had shown poor uptake of the service among female health workers (Lyimo and Beran, 2012). There is minimal information describing the uptake of CCS in this population in Kenya and particularly workers in female health workers in Kisumu County, hence the need for this study.

This study aimed at finding out the proportion of female health workers in Kisumu county that have undertaken cervical cancer screening services considering that they form part of the 
community. Knowledge of cervical cancer in this group and what the barriers are that led to minimal uptake of the services given the opportunity presented to them was to generate information that would be used by the $\mathrm{MOH}$ in adopting strategies that help to improve existing reproductive health programs. Knowledge obtained through this study would help reduce the morbidities and mortalities associated with cervical cancer hence improving the quality of life of women as a whole.

The study site was chosen because it serves a population with a $1.3 \%$ prevalence of cervical cancer screening among the female of reproductive age who have been found to be HIV positive (Mungo et al., 2013). This is in addition to being one of the leading counties with high general burden of HIV prevalence of $17.5 \%$ and a prevalence of $17.4 \%$ among women, which is a risk factor to acquiring cervical cancer. (NASCOP, 2020)

\subsection{Justification of the study}

Female health workers are expected to be in a better position to create a wider range of awareness on the importance of cervical cancer screening. This however was not the case as was determined in female health workers in Enugu, Nigeria (Ugwu et. $a l ., 2013)$ which showed that the knowledge of cervical cancer screening among female health workers, especially nurses and clinicians is high while the uptake rate is abysmally poor. There is therefore need to establish the knowledge of and uptake of cervical cancer screening, and the barriers to uptake in this group to aid in coming up with recommendations and strategies that can improve cervical cancer screening uptake.

\subsection{Objectives \\ 1.3.1. General Objective}

To determine the factors associated with uptake of cervical cancer screening services among female health workers in level 4 health facilities in Kisumu County

\subsubsection{Specific objectives}

1. To determine the proportion of female health workers who have undergone cervical cancer screening among female health workers in level 4 health facilities in Kisumu County.

2. To establish the knowledge of cervical cancer and cervical cancer screening among female health workers in level 4 health facilities in Kisumu County.

3. To assess the attitude towards cervical cancer screening of female health workers in level 4 health facilities in Kisumu County.

4. To assess the barriers to cervical cancer screening among female health workers in level 4 health facilities in Kisumu County.

\subsubsection{Research questions}

1. What is the proportion of female health workers in level 4 health facilities that have undergone cervical cancer screening in Kisumu County?

2. What is the extent of knowledge on cervical cancer screening among female health workers in level 4 health facilities in Kisumu County?

3. How is the attitude of female health workers in level 4 facilities in Kisumu County associate with the uptake of cervical cancer screening?
4. What are the barriers to uptake of cervical cancer screening services among female health workers in level 4 health facilities in Kisumu County?

\section{LITERATURE REVIEW}

\subsection{Introduction}

This chapter reviewed literature related to factors associated with uptake of cervical cancer screening services among female health workers and this was achieved by the following specific objectives; determining the proportion of female health workers who have undergone cervical cancer screening, establishing the knowledge of cervical cancer and cervical cancer screening among female health workers, assessing the attitude of female health workers towards cervical cancer screening and lastly identifying the barriers of uptake of cervical cancer screening among female health workers.

\subsection{Natural history of cervical cancer}

Cervical Cancer is a malignant neoplasm of the cervix uteri. It may present with vaginal bleeding but symptoms may be absent until the cancer is in its advanced stages. Treatment consists of surgery in early stages, chemotherapy and radiotherapy in advanced stages. If premalignant disease or cervical cancer is detected early through screening, it can be monitored or treated relatively non-invasively (Edmonds, 2007).

It has been estimated that the prevalence of HPV in cervical cancer is $99.7 \%$, and that two subtypes of the virus HPV16 and HPV 18 are present in more than $80 \%$ of invasive cervical cancers. The level of protection women gain as a population by regular screening, and the number of tests they will need in a lifetime, have been calculated by WHO. Annual screening smears provide a $93.5 \%$ reduction, a smear every 2 years provides a $92.5 \%$ reduction, 3-yearly smears provide a $90.8 \%$ reduction, 5-yearly smears provide $83.6 \%$ reduction and a smear test every 10 years has a benefit with a $64.1 \%$ reduction in incidence of cervical cancer (Javed H and Risvi N, 2006).

\subsection{Cervical cancer screening}

Screening refers to a public health intervention provided to an asymptomatic target population in order to identify individuals at high risk of developing a medical condition of note for possible intervention. It's undertaken to identify individuals with increased probability of having either the disease itself or a precursor of the disease. Cervical cancer screening herein refers to the utilization of methods used to determine whether or not an individual has lesion suggestive of cancer such as VIA and VILI. According to National Guidelines for Cancer Management Kenya (2013) the screening cycle is as follows; once every 5 years except for HIV infected women and those with abnormal tests. All HIV positive women aged 18 years and above should be screened for cervical cancer. Screening should begin at diagnosis of HIV, 6 monthly in the first year, then yearly thereafter (Ibid.).

Oche et al. (2013) showcased a 10\% uptake of cervical cancer screening in female health workers at Usmanu Danfodiyo University Teaching Hospital, Nigeria, this despite $98 \%$ of them having good knowledge about cancer of the cervix, and $90 \%$ acknowledging that it can be detected early through screening. In Uganda for example, a study revealed that $4.8 \%$ of the respondents 
had been screened for cervical cancer, with $48 \%$ of those screened did so because it had been recommended by a health worker. (Ndejjo et al. 2016).

\subsubsection{Effects of Cervical Cancer Screening on Associated Morbidities and Mortalities}

Screening for cervical cancer leads to the reduction of cervical cancer by detecting and treating cases of pre-cancer before they progress to obvious cancer. It also offers the best chance to have cervical cancer found early when successful treatment is possible.

Lack of screening will lead to late diagnosis of the disease which increases the chances of morbidity, mortality and increased socioeconomic impact to the individual in terms of financial constraint and the economy.

A study done in Argentina found out that $45 \%$ of the patients have reduced hours in work, $28 \%$ had work interruption, $39 \%$ loss of family income, $38 \%$ sale of property or use of savings (Arossi et al, 2007).

\subsection{Proportion of female health workers who have undergone cervical cancer screening.}

Female healthcare workers are supposed to provide patients under their care information about the availability and benefits of undertaking cervical cancer screening. Studies among these health professionals have shown that very few have actually had a cervical cancer screening at least once in their life despite the service being easily accessible to them. A study of cervical screening in a tertiary institution of Niger delta established that nearly over $80 \%$ of respondents (students and staff) had not been screened for cervical cancer, this despite a 56.2\% and 36\% awareness among students and staff respectively (Owoeye and Ibrahim, 2013). These finding reiterates that awareness and knowledge does not always translate into practice. Similarly, in a study among female workers in Enugu, Southeast Nigeria, it was realized that out of the $91 \%$ respondents who knew Pap smear as a test for screening precancerous lesion, only $15.5 \%$ had done the screening in the past (Ugwu et al., 2013).

Understandably, education known as the source of knowledge and should make one relatively aware of pertinent issues of life, does not solely translate into practice. It is a paradox that whilst health care workers undergo training on cervical cancer and early diagnosis through screening tests, they themselves have been known and shown not to undertake timely and regular screening as recommended by the national and international guidelines. This is true as was depicted in Nigeria through a study which revealed that $70 \%$ of the respondents who had a repetitive medical check-up and screening for cervical cancer were in the age range of 31-50 years, and results provided a significant relationships between age and routine medical checkup and screening for cervical cancer. Only $39.8 \%$ of the respondents had ever been screened for cervical cancer, with $30.1 \%$ of the respondents being in the last three years of that study. Majority of the respondents at $59.8 \%$ did not commend of making cervical cancer screening a condition for social benefits (Jagun and Ekundayo, 2016).
This study will not only identify the proportions of those who have been screened, but it will also come up with strategies on how the health workers can be motivated to do the tests.

\subsubsection{Demographic characteristics associated with uptake of cervical cancer screening.}

Socio-demographic factors such as age, education, marital status and parity have been documented as determinants of an individual's participation in cervical cancer screening. Cancer of the cervix tends to occur in mostly in women between the ages of 20 to 50. It has been noted that it rarely occurs in women who have been getting regular tests to screen for cervical cancer before they turn 65 (ACS, 2017).

A study in Nairobi, Kenya, among female patients in Kenyatta National Hospital (Gichinga et al., 2003) indicated that cervical cancer patients were more likely to be those married in a polygamous relationship. They were more likely to lack formal education and to have had their first pregnancy when less than 18 years old. The patients were also more than nine times likely to have had more than four pregnancies and also have $55 \%$ reported use of family planning as compared to $45 \%$ of non-cancer patients. Bhagwan et al (2007) revealed that age, marital status, level of education, household size, parity and contraceptive use were significantly associated with cervical cancer screening uptake. According to the study, cervical cancer screening attendance was higher among women who were young, married and had higher level of education. Additionally those living in households with 34 people and those who had ever used contraception also had higher levels of cervical cancer attendance.

A Study done in Tanzania showed that, women who reported higher approval for screening by their husbands were more likely to have been screened compared to those who had not screened. Also, fewer participants with secondary education or less had screened for cervical cancer compared to those with college education (Cunningham et al., 2015)

\subsection{Knowledge and attitude on cervical cancer and screening among female health workers.}

A person's education status is assumed to reflect the level of knowledge one has acquired, for instance, through exposure, experience and broad readership, one is expected to be more liberal and empowered compared to someone with limited education or none at all. It is expected that education plays a significant role in influencing uptake of contemporary services such as CCS. Moreover, it is generally presumed that persons with advanced education tends to make overall better choices in life, or have an edge on health seeking behavior compared to those with relatively lower education status. Most healthcare workers, at the minimum have a college level training, thus are in better position to access and make use of available health facilities and resources. Additionally, it is expected that they would have better knowledge, positive attitude and good practice of scientific procedures which they should be good ambassadors.

A study conducted in Nigeria (Ugwu, and Ezechukwu et al., 2013) among female healthcare providers found out that $91 \%$ of them were aware of the Pap smear test and $71.4 \%$ were willing to use the Pap smear for screening. Of those aware of the Pap smear test, $15.5 \%$ of them had done cervical cancer screening. The $84.5 \%$ did not give a reason for not testing however they were

This publication is licensed under Creative Commons Attribution CC BY.

http://dx.doi.org/10.29322/IJSRP.11.08.2021.p11639

WWW.ijsrp.org 
hopeful they would do the test in future. These trends are associated with poor health seeking behavior and attitude towards seeking routine preventive medical procedures. Hence need for this study in this area where there is minimal information on the uptake of the screening services.

Study in Tanzania Women who had been screened were less likely to report embarrassment than those who had not screened. Also, women who had screened were less likely to consider it painful than women who had not screened. Fear of receiving cervical cancer screening results, and concern about risk did not differ between those who had, or had not, screened.(Lyimo and Beran, 2012)

A similar study conducted in Murtala Mohammed Specialist Hospital (Kabir et al., 2005) on awareness and practice of cervical cancer screening among female health professionals found that over $60 \%$ of the respondents were able to correctly identify all the important etiological factors associated with cancer of the cervix, while a similar percentage knew the important signs and symptoms of the disease. Up to $94.7 \%$ had a positive attitude towards Pap smear while $8.2 \%$ disapproved of it. Only $20.8 \%$ of the respondents had had a Pap smear done previously, married respondents were more than four times likely to have had a previous Pap smear compared to single female health care workers. The study concluded that despite a moderately high level of knowledge of cervical cancer screening and positive attitude towards it, the uptake of Pap smear was low.

In a study carried out in Kenyatta National hospital (KNH) aimed at finding out the knowledge and practice about cervical cancer and pap smear tasting among patients attending the facility, $51 \%$ of the respondents were aware of cervical cancer while $32 \%$ knew about the Pap smear testing with $82 \%$ of healthcare workers being the primary source of information about the pap smear testing. Only $22 \%$ of the patients had had a Pap smear test most of who are among the ones who had knowledge and were aware about cervical cancer and cervical cancer screening (Gichingi et al., 2003). This study concluded that the level of knowledge and awareness about cervical cancer and cervical screening was low among Kenyan women hence need to increase level of knowledge through health education.

\subsection{Barriers to uptake of cervical cancer screening among female health workers.}

Cervical cancer screening in women of reproductive age has become very significant in this era of HIV related illnesses. It is therefore recommended by WHO that all women of reproductive age should undergo a cervical cancer screening at least once every 5 years for those who are HIV negative and yearly for those who are HIV positive. However, like observed in the general population, not all women take the initiative to request for cervical cancer screening. Female health care workers are not excluded.

\subsubsection{Inter-personal barriers}

In a study among medical workers in a Ugandan hospital (doctors, nurses and medical students) only 19\% of the female medical workers had ever had a cervical cancer screening test done. The reasons for not having been screened included: not feeling at risk, lack of symptoms, carelessness, fear of vaginal examination, lack of interest, test being unpleasant and not yet being of risky age (Mutyaba and Mmiro, 2011). These findings are in consonance with study by Ndejjo et. al., (2016) that also revealed personal perception related reasons such as having no signs and symptoms, not being at risk and fear of the screening outcomes, in $64.5 \%$ of respondents who had been screened as their main reasons. Similarly, in Sokoto, Nigeria, $34.4 \%$ of participants opined that only women who had lived promiscouis lifestyle should undergo the test (Oche et. al., 2013)

\subsubsection{Social cultural and community barriers}

Religion, taboo and stigma related to cervical cancer questions regarding modesty, and fear of becoming isolated from one's family, and lack of freedom to make own decision on health issues by women is a notable barrier. These are reiterated by Dsouza et al., (2020) who demonstrated the laxity among female nurses in a multi contextual study in India that described low uptake to be related to requirements by society to seek spousal approval for health related matters. Findings that were also determined in Federal Teaching and Referral Hospital in Ebonyi state of Nigeria (Iffemeluma et al., 2019)

\subsubsection{Health system related barriers}

Inadequate service availability is a common reason for low uptake of cervical cancer screening. A study in India revealed that, compared to $\mathrm{MOH}$ public facilities, private hospitals are better equipped with screening facilities, was perceived as an important inconvenience of the system, and cause for demotivation as most women who would desire the services will often be referred to other centers, coupled with long waiting times (Dsouza et. al., 2020).

A similar study among nurses in a Tanzanian hospital concerning nurses' own cervical cancer screening practices found out that $86.4 \%$ of the respondents had never had a Pap smear. The most common reasons for not having a Pap smear was not knowing where to go for the test $(54.7 \%)$, feeling that there is no reason for the test $(13.1 \%)$, fear of the Pap smear procedure $(9.5 \%)$ and $7.3 \%$ were afraid of undesirable results (Urasa M, 2011).

This study aimed to find out whether Kenyan female health workers share the same views or they have different views. In another study done in Kisumu, $91 \%$ of surveyed women had heard of general cancer. Only $29 \%$ of 388 surveyed women had previously heard of cervical cancer, $6 \%$ had ever been screened and the remaining cited barriers such as fear, time, and lack of knowledge. Women with perceived risk of cervical cancer were older (odds ratio 1.06, 95\% confidence interval 0.02-1.10). Five percent of women reported that they would not be willing to undergo screening regardless of cost (Sudenga, Rositch and Otieno, 2013).

\subsection{Summary of literature review}

Despite the high level of awareness of cervical cancer screening, utilization remain low (Iffemeluma et al., 2019). This is worrying given that they are expected to champion provision of such an important gateway to good and appropriate reproductive health among women. It is thus paramount that strategies be identified that can help improve uptake, if not optimal, among female health workers in sub Saharan Africa, Kenya included. This study is therefore aimed at identifying these factors and formulating strategies. 


\section{MATERIALS AND METHODS}

\subsection{Introduction}

This chapter describes the methodology that was used to conduct the study, thus included the research design, study population, sample and sampling procedure. It also featured the data collection procedures, methods of data analysis, operational definition of variables and ethical considerations.

\subsection{Study site}

This study was conducted in Kisumu County. Kisumu County borders Siaya County to the west, Vihiga County to the north, Nandi County to the north east, Kericho County to the east, Nyamira to the south and Homa Bay County to the south east. It runs along the shores of Lake Victoria to the northwest and south of Winam gulf. Kisumu County has an estimated total population of 968,909 , covering an area of $2,085.9 \mathrm{sqKm}$, with a population density of 460 persons per sqKm. (Kenya National Bureau of Statistics, 2010)

Administratively, Kisumu County is divided into seven sub counties namely; Kisumu east, Kisumu west, Kisumu central, Muhoroni, Nyakach, Nyando and Seme. These are further divided into 35 wards. The major economic activities practiced in the region are fishing in the vast Lake Victoria, rice planting in the Kano plains with irrigation from river Nyando, and sugar cane farming.

In 2015, Kisumu County had a total of 190 health institutions; 112 public, 17 non-governmental, 17 faith based organizations and 44 privately owned hospitals. In the same year, the region reported a $73.1 \%$ full immunization rate amongst 12 23 months old, a tuberculosis prevalence of 306 and Malaria case identification of 46,444 per 100,000 population respectively. This, in addition to HIV prevalence rate of $17.5 \%$ and $17.4 \%$ among women (NASCOP, 2020). The region has a nurse to patient ration of 1:3333 and a doctor to patient ratio of 1:5000 (Ministry of Health, 2015).

\subsection{Study design} sectional study that utilized both quantitative and qualitative approaches to data collections. A descriptive study approach was chosen because it provided room for the exploration and description of phenomena in real life situation (Polit and Becker, 2010). It provided an accurate account of characteristics of particular individuals or groups.

Mugenda and Mugenda (2003) further denote that this design is appropriate when the purpose of the study is to create a detailed description of an issue. The quantitative approach helped reveal the relationship between the variables, while the qualitative approach helped in bringing out the attitudes, opinions and experiences that explain the behavior of the population, hence obtaining an in-depth understanding of factors that influence uptake of cervical cancer screening by female health workers.

A focused group discussion (FGD) qualitative research approach was adopted because its iterative data collection method and research questions format helps in determining the knowledge insights and spectrum for any service or program. The participants are able to share information with the researcher in their own words and from their own perspective (Charmaz Kathy, 2006).
This study adopted a facility based descriptive cross

\subsection{Operationalization of study variables}

Independent variables represent background characteristics. This was assessed through questions related to socio demographic factors like age, profession, education level, marital status, religion and parity.

Intermediate variables were assessed through questions related to knowledge of cervical cancer and cervical cancer screening, screening methods, risk factors to cervical cancer, cure for cervical cancer, and frequency of testing. Attitude towards cervical cancer screening were assessed through questions testing if the respondent feels at risk of cervical cancer, acceptance/decline of screening and willingness to pay for screening services. Practice was assessed through questions testing whether the respondent has ever had a screening test and if so the number of times.

Dependent variable was assessed through questions related to the proportion of respondents who have been screened, percentage of respondents who have never been screened.

\subsection{Study population}

The study's target population was Kisumu County female health workers aged 18 years and above working within Kisumu, Migosi, Kombewa and Ahero Sub County Hospitals. The facilities were chosen because they were all level 4 hospitals, and according to health profile are expected to have better nurse to patient ratios, diagnostic and treatment facilities.

According to human resource statistics with the County Chief Operations Officer (COO), as at June 2016, there were a total of 1066 female health workers in the whole of Kisumu County. Further, the staff distribution at the time in the four selected study sites was as highlighted in Table 3.1 below.

\section{Table 3.1. The distribution of female health care workers in the study sites}

\begin{tabular}{ll}
\hline $\begin{array}{l}\text { Distribution of female health workers in the selected study } \\
\text { sites (n= 339) }\end{array}$ \\
\hline Name of Facility & Staff Frequency \\
\hline Kisumu County Hospital & 149 \\
Migosi Sub County Hospital & 88 \\
Kombewa Sub County & \\
Hospital & 77 \\
Ahero Sub County Hospital & 25 \\
\hline
\end{tabular}

The study population included female health workers working in the level 4 health facilities within Kisumu County, who had come into contact with patients for more than a month.

\subsubsection{Inclusion criteria}

All female health workers on duty at the time of the study aged 18 years and above that had worked at the health facility for more than one month and were willing to participate in the study by signing a consent. This criterion was identified because the health workers were presumed to not only have come into contact with clients, but would also have had a chance or opportunity presented to them to undertake cervical cancer screening.

\subsubsection{Exclusion criteria}

This publication is licensed under Creative Commons Attribution CC BY

http://dx.doi.org/10.29322/IJSRP.11.08.2021.p11639

www.ijsrp.org 
All female health workers who had worked at the health facilities for less than one month, equally those who failed to consent were excluded.

\subsection{Sample size determination}

The target population being all female health workers working in Kisumu County Hospital, Migosi, Kombewa and Ahero Sub County Hospitals. Yamane (1967) formula was employed at a 5\% margin of error to get the desired sample size. This formula was chosen because the study utilized a finite population size which was known.

Therefore' $\quad \mathrm{n}=\mathrm{N} /\left(1+\mathrm{Ne}^{2}\right)$

Where $\mathrm{n}=$ desired sample size

$\mathrm{N}=$ (339) finite population size (HR records as

at June 2016, Kisumu County)

$$
\mathrm{e}=\text { margin of error }
$$

Thus, employing the above formula, the study sample size arrived at was;

$$
\mathrm{n}=339 /(1+339(0.05 \times 0.05)=183.49
$$

Given that one can never have fraction of human participants, the sample size was then rounded off to the nearest whole number giving 184 . To cater for probable non-response, a ten percent contingency buffer was adopted to give a final sample size of 203

\begin{tabular}{|c|c|c|c|}
\hline Facility & $\begin{array}{l}\text { Total female } \\
\text { Staff }\end{array}$ & $\begin{array}{l}\text { Proportion } \\
(\%)\end{array}$ & $\begin{array}{l}\text { Sample } \\
\text { size }\end{array}$ \\
\hline $\begin{array}{l}\text { Migosi sub county } \\
\text { Hospital }\end{array}$ & 88 & 26 & 53 \\
\hline $\begin{array}{l}\text { Kisumu county } \\
\text { Hospital }\end{array}$ & 149 & 44 & 89 \\
\hline $\begin{array}{l}\text { Ahero sub-County } \\
\text { Hospital }\end{array}$ & 25 & 7 & 14 \\
\hline $\begin{array}{l}\text { Kombewa sub } \\
\text { County Hospital }\end{array}$ & 77 & 23 & 47 \\
\hline Total & 339 & 100 & 203 \\
\hline
\end{tabular}

Table 3.2. Sample distribution

This sample was then proportionately allocated to the various study sites as highlighted in Table 3.2 above where a proportion of total number of female staff in a given facility was calculated against the cumulative female staff, that is, the numerator being facility specific number of female staff and the denominator being total female staff in all the 4 study sites.

To determine the sample size for qualitative respondents, the researcher employed recommendations by the Archive for Sexual behavior (Shari L. Dworkin. , 2012), which states that 2530 participants is the minimum sample size required to reach saturation and redundancy in qualitative research studies that use either in-depth interviews or focused group discussions. A total of four FGD groups were identified, each from the study sites constituting a modal class of 6 . Discussions were then held, guided by semi structured questions that had been prepared.

This number is considered adequate because it not only allows for thorough examination of the characteristics that address the research question, but also maximizes the possibility that enough data have been collected to clarify relationships between conceptual categories while identifying variations in the process (Charmaz Kathy, 2006).

Considering time and availability of study participants, the lower limit of 25 was settled on by the researcher. These were then distributed uniformly across the four facilities resulting into sample frame as shown in, Table 3.3 below except for Kisumu County Hospital which had one extra participant:

\section{Table 3.3. Sample distribution for the FGDs}

\begin{tabular}{lll}
\hline Facility Name & Population & Sample size \\
\hline Migosi sub County Hospital & 88 & 6 \\
Kisumu County Hospital & 149 & 7 \\
Ahero sub County Hospital & 25 & 6 \\
Kombewa sub County & 77 & 6 \\
Hospital & & \\
Total & $\mathbf{3 3 9}$ & $\mathbf{2 5}$ \\
\hline
\end{tabular}

\subsection{Sampling Techniques}

The four health facilities were selected purposively due to similar characteristics shared among them detailed above. The study sample size of 203, was proportionately allocated to the four health facilities and respondents selected using systematic random sampling. The sampling frame comprised of a list of all the female health workers in the specific health facilities generated from the hospital human resource records with the first being the longest serving in the facility.

A systematic random sampling was employed at each facility with, every second name in the list was identified as participant and was interviewed. This was arrived at by dividing the target population per facility by the sample size based on facility, for instance; Migosi at $88 / 53=1.66$, Kisumu County at $149 / 89=1.67$, Ahero at 25/14=1.78, and Kombewa at 77/47=1.64. All these rounded off to the nearest person result to 2. Every second person in the list was selected for each facility as the first participant. The cycle was repeated until desired sample size was arrived at.

\subsection{Data collection tools}

Self-administered semi structured close ended questionnaires was used to engage the participants at the time of their convenience. Semi structured questionnaires (some questions were open ended) was opted for because they were a relatively quick method of data collection, the responses were collected in a standardized way. Qualitative data was collected using focused group discussion (FGD) sessions. FGDs were opted for because they permit exploration of additional points when required by means of explanation.

\subsection{Pre testing of data collection tools}

Pre- testing for the questionnaire was done at Siaya County Referral Hospital. This facility was chosen because it is situated in Siaya County, a Level four referral hospital that serves a population which offers similar characteristics to the study target population such as varying levels of education, religious affiliations and exposure to information. A sample size of 1-10\% suffices (Mugenda M and Mugenda G, 1999), therefore in this case, a sample size of 20 patients were recruited for pre- testing. 


\subsection{Data Collection Process}

A research proposal was written then submitted for approval through the academic supervisors. With their consent, the researcher then applied for permission to conduct the study from Baraton University Ethics and Review Committee and was granted. This was then presented to Medical Superintendents of Ahero sub County, Migosi Sub County, Kisumu County and Kombewa Sub County Referral Hospital seeking authorization and permission to conduct the study as indicated in appendices. Structured questionnaire was opted for because besides them being a relatively quick method of data collection, the responses are collected in a standardized way, additionally, the same information is collected from all participants in comparable and pre-specified way (Polit and Becker, 2010).

A total of four FGDs were conducted one in each of the health facilities. In order to encourage free exchange of ideas and expression of practice, the sessions were held in the afternoon, this is because at these times workload is usually minimal since most clients have been attended to and discharged. The discussions were in English language using an FGD guide that had been developed prior and lasted approximately 45-60 minutes without interference. Audio recording of the sessions was done, and hand written notes taken by the moderator to supplement the audio records.

\subsection{Data management and analysis}

At the end of day, completed questionnaires were collected, edited for completeness, appropriateness and accuracy, while limiting probable errors. These were then entered into Statistical Packages for Social Sciences (SPSS) version 20. The study employed descriptive statistics to analyze data obtained; and these included the use of frequencies and percentages. This technique enabled the researcher to meaningfully describe a distribution of scores using few indices (Mugenda, Olive M. and Mugenda Abel G., 2003).

The study utilized chi square test of inferential statistics between the independent and dependent variables. A chi square test was appropriate because the sampling method was simple random, variable understudy were categorical and most level of the categorical variables had an expected frequency of at least five (Denise F. Polit, and Cheryl T. Becker, 2010). Moreover, chi square is used to test how likely it is that an observed distribution is due to chance, or how well the observed distribution fits with the distribution that is expected if the variables are independent.

To determine the proportion of female health workers who have undergone cervical cancer screening in level 4 health facilities in Kisumu County and its association to uptake of cervical cancer screening among female health workers, data was collected on female health workers age, marital status, religion, profession and education level. These were then analyzed using descriptive statistic and results presented using frequency distribution tables. A chi square test of association was used to determine the association between female health workers demographic characteristics and uptake of CCS and statistically significant ones highlighted.

To establish the association between knowledge of cervical cancer screening and its uptake among female health workers in level 4 health facilities in Kisumu County, data was collected on knowledge of risk factors, methods of cervical cancer screening, age at which cervical cancer commonly occur in women and frequency of screening. The findings were analyzed using descriptive statistics and presented as frequencies and proportions. Subsequently, Likert scale was employed to capture data with reference measures of central tendency such as mean, median and standard deviations and their association to uptake of cervical cancer screening among female health workers

To assess the attitude of female health workers on cervical cancer screening and how it is associated with uptake among female health workers in Kisumu County, data was collected on acceptance to be screened, willingness to pay for cervical cancer screening, and whether or not one considered herself to be at risk. The findings were analyzed using descriptive analysis and chi square test of association which were then presented in frequency tables.

To identify barriers to cervical cancer screening and its influence on the uptake among female health workers in level four hospitals in Kisumu County, data was collected on having had a cervical cancer screening, and if yes, how many times, if not why? These were analyzed using descriptive statistics and presented as frequency tables and proportions.

Qualitative data was collected on knowledge and attitude of female health workers; and potential barriers to the uptake of cervical cancer screening. The audio recordings were then transcribed and read by the researcher for familiarity with the data. Data was coded and analyzed using direct content analysis with the help of Atlas.ti v.6.0.15 qualitative data management software. Direct quotations from the FGDs are presented in italics to highlight the key findings guided by criteria for reporting qualitative research (COREQ-32).

\subsection{Ethical Consideration}

Permission to conduct the study was sought through application for ethical approval from Baraton University, whose ethical review committee is accredited by NACOSTI. Further permission was sought from the Ministry of Health through the offices of the Medical Superintendent, Kisumu County hospital, in charges of Migosi, Kombewa and Ahero sub County hospitals and Siaya District Hospital.

Prior to recruitment, the researcher and research assistants sought written informed consent from participants. The targeted participants were explained to on who was conducting the study, what was the purpose of the study, what the researcher hoped to achieve by conducting this study, the consent form further stated how the findings of the study were beneficial to the participant, the society and the health system as a whole.

The participants were informed of possible risks that may arise from the study. Importantly, the participants were told the number of times that the research assistants were in contact with her. Finally, the participants were assured that the researcher would take all the necessary precaution and steps to protect her privacy and confidentiality, no name was used in the questionnaire and the participant were only be identified by a code that only the researcher can link to the actual individual.

\section{RESULTS}

\subsection{Introduction}


This chapter presents the results of the study. The chapter begins by describing the demographic characteristics of the female health workers in Level 4 health facilities in Kisumu County who participated in the study. It is then followed by the substantive findings according to the research objectives.

\subsection{Research participants response rate}

A response rate of $50 \%$ is considered or deemed adequate for analysis and reporting, however, a response rate of $60 \%$ is considered good, of $70 \%$ and over is very good (Mugenda, Olive M. and Mugenda Abel G., 2003).

Table 4.1. Participant's response rate

\begin{tabular}{llll}
\hline $\begin{array}{l}\text { Target } \\
\text { Population }\end{array}$ & $\begin{array}{l}\text { Sample } \\
\text { Size }\end{array}$ & $\begin{array}{l}\text { Returned } \\
\text { questionnaires }\end{array}$ & $\begin{array}{l}\text { Return } \\
\text { rate }(\boldsymbol{\%})\end{array}$ \\
\hline 338 & 203 & 191 & 94 \\
\hline
\end{tabular}

Table 4.1 above reveals that out of the 203 copies of questionnaires administered to the study respondents, 191 were returned duly completed indicating a response rate of $94 \%$. It therefore suffices to record that the study had an excellent return of response rate. This was attributed to the fact that the researcher made use of self-administered questionnaires which were filled at respondents own discretion, and therefore 12 respondents failed to return their questionnaires back.

\subsection{Participants demographic characteristics}

This section outlines the respondent's demographic features that were believed to be significant to the study. Such demographic characteristics include age, gender, and marital status, level of education, occupation and religion. These demographic characteristics of respondents were considered on the premise that such variations could influence uptake of HIV testing.

\subsubsection{Characteristics of participants by age}

In this study, it was assumed that age variations of the respondents would be of great significance on the grounds that individuals of reproductive health bracket, 20-49 years old, would be expected to be more liberal and welcome to ideas that will go towards improving their health and treatment outcomes. The participant's responses have been indicated in Table 4.2 below:

Table 4.2. Participant's age

\begin{tabular}{|c|c|c|c|}
\hline \multicolumn{4}{|c|}{ Characteristics of study participants by age $(\mathrm{N}=191)$} \\
\hline $\begin{array}{l}\text { Participants } \\
\text { age }\end{array}$ & & Frequency & Percentage \\
\hline & $18-24$ years & 46 & 24.0 \\
\hline & $25-32$ years & 83 & 43.5 \\
\hline & $33-40$ years & 44 & 23.0 \\
\hline & $41-49$ years & 18 & 9.4 \\
\hline & Total & 191 & 100.0 \\
\hline
\end{tabular}

As indicated in Table 4.2 above, 46 (24\%) of the respondents whose questionnaires were received were of age 1824 years, $83,(43.5 \%)$ were in the age of $25-32$ years, $44(23 \%)$ were in the age of 33 - 40 years, while $18(9.4 \%)$ fell between 41 to 49 years. The statistic in Table 4.2 show that the population consisted nearly a half were of reproductive health bracket of 25 to 32 years comprising $83(43.5 \%)$ of the respondents. This is a pointer that the largest population of female health workers in Kisumu County are relatively young.

\subsubsection{Characteristics of participants by religion}

Religion was consider relevant by the researcher in this study given the perceived practices amongst different religious groups, especially regarding reproductive health services. It was in the prism of this that the researcher sought to determine religious affiliations of the study participants. 


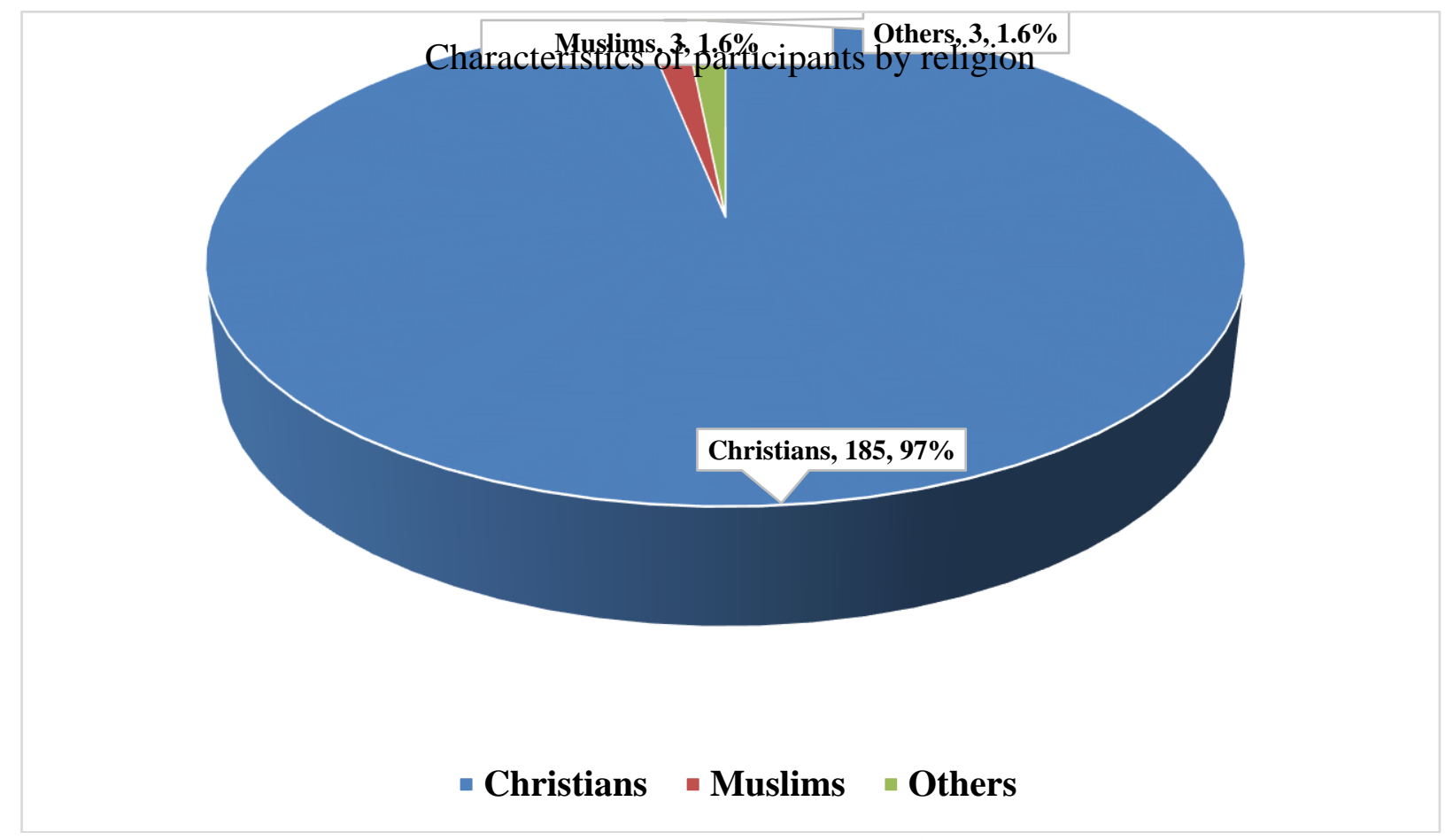

Figure 4.1. Participant's religious affiliations

The statistic in Figure 4.1. above, indicates that out of the 191 questionnaires returned duly filled by the respondents, Christians were 185 (97\%) while Muslims were 3 (1.6\%) with others whose religious affiliation was not indicated being 3 $(1.6 \%)$. The vast majority of study participants were Christians.

\subsubsection{Characteristics of participants by occupation}

In this study, the researcher attempted to determine whether differences in occupations could influence uptake of cervical cancer screening by female health workers. This was because, presumably, individuals with direct contact with female patients play critical role in educating them on importance of cervical cancer screening, and how valuable it is coming from one who not only is the custodian of knowledge, but also has undergone screening themselves and are living out its benefits. It was on the account of this, that the respondents were requested to state their current occupation and responses noted as illustrated in Table 4.4 below.
Table 4.4. Participant's occupation

\begin{tabular}{lll}
\hline Characteristics of participants by occupation & $(\mathbf{N}=191)$ \\
\hline Respondents occupation & Frequency & Percentage \\
\hline Community health worker & 19 & 9.9 \\
Clinical officer & 37 & 19.3 \\
Health records officer & 2 & 1.0 \\
HTS counselor & 23 & 12.0 \\
Laboratory technologist & 4 & 2.1 \\
Medical officer & 6 & 3.1 \\
Nurse & 69 & 36.0 \\
Nutritionist & 21 & 10.9 \\
Occupational/physiotherapist & 3 & 1.6 \\
Peer educator & 5 & 2.6 \\
Pharmacy & 2 & 1.0 \\
Total & $\mathbf{1 9 1}$ & $\mathbf{1 0 0 . 0}$ \\
\hline
\end{tabular}

Table 4.4 above reveals that out of the 191 questionnaires returned by respondents duly completed, 69 (35.9\%) were nurse, $37(19.3 \%)$ indicated they were clinical officers, $23(12 \%)$ were in HTS counselors, $21(10.9 \%)$ were nutritionists, while $6(3.1 \%)$ were medical officers. Peer educators, pharmacy and lab personnel were fewer. The above statistics demonstrate that majority of respondents were nurses and clinical officers.

\subsubsection{Characteristics of participants by level of education}


The researcher sought to determine how the level of education would significantly influence respondents uptake of cervical cancer screening due to exposure to contemporary health practice, and awareness of health benefits of knowing individuals cervical cancer screening outcomes, especially where the respondents were educated.

The participant's responses are documented in Table 4.5 below, which expectedly show that, out of the analyzed 191 questionnaires returned, $100(52.4 \%)$ of the respondents had college level education, $75(39.3 \%)$ had university level of education, with $16(8.3 \%)$ having attained secondary and primary level of education. This is because the participants were professionals.

Table 4.5. Participant's level of education

\begin{tabular}{llll}
\hline $\begin{array}{l}\text { Characteristics } \\
\text { (N=191) }\end{array}$ & of & respondents by & level of education \\
\hline $\begin{array}{l}\text { Level of } \\
\text { education }\end{array}$ & Frequency & Percentage \\
\hline Primary school & 2 & 1.0 \\
Secondary school & 14 & 7.3 \\
College level & 100 & 52.4 \\
University level & 75 & 39.3 \\
Total & $\mathbf{1 9 1}$ & $\mathbf{1 0 0 . 0}$ \\
\hline
\end{tabular}

\subsubsection{Characteristics of participants by marital status}

This characteristic was considered important to the study as it would help reveal the extent to which marital status of the respondents would influence uptake of cervical cancer screening among female health workers. The married people, unlike the singles, the widowed, divorced or separated, may be positively or negatively influenced by their spouses. At the same time, they are assumed to have greater responsibility of taking care of their immediate families hence desire to ensure they are always in good health.

In relation to these, the responses of the participants as highlighted in Table 4.6 below show that of the 191 questionnaires completely filled by the respondents, $70(36.7 \%)$ were single, 114 $(59.7 \%)$ were married, $3(1.6 \%)$ were either divorced or separated and $4(2.1 \%)$ were either widowed. This reveal that majority of the respondents were married, followed closely by those who were single. This is a clear representation of the staffing distribution in public hospitals.

Table 4.6. Participant's marital status

\begin{tabular}{lll}
\hline \multicolumn{2}{l}{ Characteristics of participants by marital status $(\mathbf{N}=191)$} \\
\hline Marital status & Frequency & Percentage \\
\hline Single & 70 & 36.7 \\
Married & 114 & 59.7 \\
Separated/Divorced & 3 & 1.6 \\
Widowed & 4 & 2.1 \\
Total & $\mathbf{1 9 1}$ & $\mathbf{1 0 0 . 1}$ \\
\hline
\end{tabular}

\subsubsection{Characteristics of participants by parity}

This measure was considered valuable by the researcher, since number of parity is directly proportional to cervical predisposition to examination and dilation exposures during clinical visits. Additionally, a health provider is likely to examine the cervix during regular antenatal visits should there be warranting complaints such as pain and bleeding. It was in light of this that the participants were asked about parity and their responses highlighted in Table 4.7 below:

Table 4.7. Participants by parity

\begin{tabular}{lll}
\hline \multicolumn{3}{l}{ Characteristics of participants by parity $(\mathbf{N}=191)$} \\
\hline Parity & Frequency & Percentage \\
\hline Nulliparous & 57 & 29.9 \\
1-4 children & 123 & 64.3 \\
$\begin{array}{l}\text { children } \\
\text { Total }\end{array}$ & 11 & 5.8 \\
Tobove & & \\
\hline
\end{tabular}

The statistic in Table 4.7 above reveal that out of the 191 questionnaires returned duly filled by the respondents, 57 (29.9\%) were nulliparous, $123(64.3 \%)$ had children between 1 and 4, while $11(5.8 \%)$ indicated to have five and above children.

\subsection{Proportion of female health workers who have undergone cervical cancer screening}

Participant's demographic characteristics have been established to influence uptake of any medical or health intervention, cervical cancer screening included, among the general population (NASCOP, 2014). This study determined that $112(58.3 \%)$ of the respondents had undergone cervical cancer screening. This variable was measured on the basis of age, religion, occupation, level of education, marital status, and parity.

\subsubsection{The influence of participants age on the uptake of cervical cancer screening}

The respondents who were enrolled in the study were asked whether they had undergone cervical cancer screening and their response was as illustrated in the 4.8 below. The statistic in the table demonstrates that $112(58.3 \%)$ of the respondents had undergone cervical cancer screening with preponderance of them $51(61.4 \%)$ being of the age bracket 25-32 years old. Notably, lower screening rate was observed among the 18-24 years old which had only $14(30.4 \%)$ having undergone cervical cancer screening. Conversely, higher screening rates were witnessed among the 33-40 years old with $34(77.3 \%)$ reporting to have had cervical cancer screening. 
Table 4.8. Cross tabulation of participant's age and uptake of cervical cancer screening

\begin{tabular}{llllll}
\hline $\begin{array}{l}\text { Age } \\
\text { (years) }\end{array}$ & Yes & No & Total & $\begin{array}{l}\text { Chi } \\
\text { test }\end{array}$ & Sq. \\
\hline $18-24$ & 14 & 32 & 46 & 2.5151 & 0.001 \\
& $(30.4 \%)$ & $(69.6 \%)$ & $(24.1 \%)$ & & \\
$25-32$ & 51 & 32 & 83 & & \\
& $(61.4 \%)$ & $(38.6 \%)$ & $(43.5 \%)$ & & \\
$33-40$ & 34 & 10 & 44 & & \\
& $(77.3 \%)$ & $(22.7 \%)$ & $(23.0 \%)$ & & \\
$41-49$ & 13 & 5 & 18 & & \\
& $(72.2 \%)$ & $(27.8 \%)$ & $(9.4 \%)$ \\
Total & $\mathbf{1 1 2}$ & $\mathbf{7 9}$ & $\mathbf{1 9 1}$ & & \\
& $(\mathbf{5 8 . 3 \% )}$ & $\mathbf{( 4 1 . 1 \% )}$ & $(\mathbf{1 0 0 . 0 \% )}$ & \\
\hline
\end{tabular}

The study found out that there is an association between age and CCS. A chi square test result of 2.151 with a $\mathrm{p}$ value of 0.001 at a confidence interval of $95 \%$, is less than the $p$ value of 0.05 , therefore denoting a statistically association between respondent's age and cervical cancer screening. The study therefore deduced that respondent's age significantly influences uptake of cervical cancer screening.

\subsubsection{The influence of participants religion on the uptake of} cervical cancer screening

The participants were asked to identify their religious affiliations and their responses were as highlighted in Table 4.10 below.

Table 4.10 Cross tabulation of religion and uptake of cervical cancer screening

\begin{tabular}{llll}
\hline $\begin{array}{l}\text { Cross tabulation of participants religion and cervical cancer } \\
\text { screening }(\mathbf{N = 1 9 1 )}\end{array}$ \\
\hline \multicolumn{5}{c}{ Cervical Cancer Screening } \\
\hline Religion & Yes & No & Total \\
\hline Christian & $108(58.1 \%)$ & $78(41.9 \%)$ & $186(97.4 \%)$ \\
Muslim & $3(100.0 \%)$ & $0(0.0 \%)$ & $3(1.6 \%)$ \\
Others & $1(50.0 \%)$ & $1(50.0 \%)$ & $2(1.0 \%)$ \\
Total & $\mathbf{1 1 2}(\mathbf{5 8 . 3 \%})$ & $\mathbf{7 9}(\mathbf{4 1 . 1 \% )})$ & $\begin{array}{l}\mathbf{1 9 1} \\
\mathbf{( 1 0 0 . 0 \% )}\end{array}$ \\
\hline
\end{tabular}

Table 4.11. Chi sq. test of religion and screening uptake Chi square tests of association

$\begin{array}{lll}\text { Value df } & \begin{array}{l}\text { Asymp. Sig. } \\ (2-\text { sided })\end{array}\end{array}$

\begin{tabular}{llll}
\hline $\begin{array}{l}\text { Pearson Chi- } \\
\text { Square }\end{array}$ & $1.942 \mathrm{E} 2^{\mathrm{a}}$ & 6 & 0.001 \\
Likelihood & 15.798 & 6 & 0.015 \\
Ratio & & & \\
$\mathrm{N}$ of Valid & 191 & & \\
Cases & & &
\end{tabular}

a. 10 cells $(83.3 \%)$ have expected count less than 5 . The minimum expected count is .01 .

The statistic in Table 4.10 above demonstrates that nearly half of the study participants at $108(58.1 \%)$ who reported to be Christians had undergone cervical cancer screening, with onehundred percent screening among the Muslims. Nonetheless, Table 4.11 above shows that at $95 \%$ confidence interval; a chi square statistic of 1.942 , and a p value of 0.001 , which is less than 0.05 , demonstrates a statistically significant association between religion and cervical cancer screening.

\subsubsection{The influence of participant's occupation to uptake of cervical cancer screening}

Tables 4.12 and 4.13 below describes the cross tabulation of cervical cancer screening and respondents occupation, and chi square analysis as was elucidated by the study.

Table 4.12. The influence of participant's occupation on uptake of screening

Participants' occupation and cervical cancer screening (N=191)

\begin{tabular}{llll}
\hline & $\begin{array}{l}\text { Cervical } \\
\text { screening }\end{array}$ & \multicolumn{1}{c}{ cancer } \\
\hline Occupation & Yes & No & Total \\
\hline Community health worker & 11 & $8(42.1 \%)$ & $19(9.9 \%)$ \\
& $(57.9 \%)$ & & 37 \\
Clinical officer & 29 & $8(21.6 \%)$ & $(19.4 \%)$ \\
Health records officer & $(78.4 \%)$ & & $2(1.0 \%)$ \\
HTS counselor & $1(50.0 \%)$ & $1(50.0 \%)$ & 23 \\
& 14 & $9(39.1 \%)$ & $(12.0 \%)$ \\
Laboratory Technologist & $2(60.9 \%)$ & $2(50.0 \%)$ & $4(2.1 \%)$ \\
Medical officer & $3(50.0 \%)$ & $3(50.0 \%)$ & $6(3.1 \%)$ \\
Nurse & 40 & 29 & 69 \\
& $(58.0 \%)$ & $(42.0 \%)$ & $(36.1 \%)$ \\
Nutritionist & $6(28.6 \%)$ & 15 & 21 \\
& $(71.4 \%)$ & $(11.0 \%)$ \\
Occupational/Physiotherapist & $2(66.7 \%)$ & $1(33.3 \%)$ & $3(1.6 \%)$ \\
Peer educator & $3(60.0 \%)$ & $2(40.0 \%)$ & $5(2.6 \%)$ \\
Pharmacy technologist & $1(50.0 \%)$ & $1(50.0 \%)$ & $2(1.0 \%)$ \\
Total & $\mathbf{1 1 2}$ & $\mathbf{7 9}$ & $\mathbf{1 9 1}$ \\
& $(\mathbf{5 8 . 3 \% )}$ & $\mathbf{( 4 1 . 1 \% )}$ & $\mathbf{( 1 0 0 . 0 \% )}$ \\
\hline
\end{tabular}

The data in Table 4.12 above illustrates that out of the 191 returned questionnaires duly filled by respondents, $112(58.3 \%)$ of 
the female health workers interviewed had been screened for cervical cancer.

Table 4.13. Chi sq. test of occupation and uptake of cervical cancers screening

\section{Chi-Square Tests}

\begin{tabular}{llll}
\hline & Value & df & $\begin{array}{l}\text { Asymp. Sig. (2- } \\
\text { sided) }\end{array}$ \\
\hline Pearson Chi-Square & $2.064 \mathrm{E}^{\mathrm{a}}$ & 22 & 0.001 \\
Likelihood Ratio & 27.297 & 22 & 0.200 \\
N of Valid Cases & 191 & & \\
\hline
\end{tabular}

To test the level of association, and at a 0.05 margin of error, a chi square test was run and a value of 2.064 with a p value of 0.001 , which is less than 0.05 was considered to be statistically significant. This study therefore determined that occupation or specific cadre of the female health care workers was strongly associated with uptake of cervical cancer screening.

\subsubsection{The influence of respondents level of education on uptake of cervical cancer screening}

It is expected that education plays a significant role in influencing uptake of cervical cancer screening. It is in light of this that the researcher chose to investigate the extent to which education level contributes to cervical cancer screening uptake, using cross tabulation between level of education and screening test for cervical cancer, the respondents and outcomes of analysis are highlighted in Tables 4.14 and 4.15 below:

Table 4.14. Cross tabulation of education level and uptake of screening

Cross tabulation of respondents level of education and cervical cancer screening uptake $(\mathrm{N}=191)$

\begin{tabular}{|c|c|c|c|c|c|c|}
\hline & & \multicolumn{5}{|c|}{ Respondents Level of Education } \\
\hline & & $\begin{array}{l}\text { Primar } \\
\mathbf{y}\end{array}$ & $\begin{array}{l}\text { Secondar } \\
\mathbf{y}\end{array}$ & College & $\begin{array}{l}\text { Universit } \\
\mathbf{y}\end{array}$ & Total \\
\hline $\begin{array}{l}\text { Have } \\
\text { you } \\
\text { been }\end{array}$ & $\begin{array}{l}\mathrm{Ye} \\
\mathrm{s} \\
\mathrm{No}\end{array}$ & $1(0.9 \%)$ & $9(8.0 \%)$ & $\begin{array}{l}58 \\
(51.8 \%)\end{array}$ & $\begin{array}{l}44 \\
(39.3 \%)\end{array}$ & $\begin{array}{l}112 \\
(58.6 \%)\end{array}$ \\
\hline $\begin{array}{l}\text { screene } \\
\mathrm{d} \text { for } \\
\text { cervical } \\
\text { cancer? }\end{array}$ & & $1(1.3 \%)$ & $5(6.3 \%)$ & $\begin{array}{l}42 \\
(53.2 \%)\end{array}$ & $\begin{array}{l}31 \\
(39.2 \%)\end{array}$ & $\begin{array}{l}79 \\
(41.4 \%)\end{array}$ \\
\hline Total & & $\begin{array}{l}2 \\
(1.0 \%)\end{array}$ & $14(7.3 \%)$ & $\begin{array}{l}100 \\
(52.1 \%\end{array}$ & $\begin{array}{l}75 \\
(39.1 \%)\end{array}$ & $\begin{array}{l}191 \\
(100.0 \%\end{array}$ \\
\hline
\end{tabular}

Table 4.15. Chi sq. test of education level and uptake of screening

Chi-Square Tests of association between level of education and cervical cancer screening

\begin{tabular}{llll}
\hline & Value & df & $\begin{array}{l}\text { Asymp. Sig. (2- } \\
\text { sided) }\end{array}$ \\
\hline Pearson Chi-Square & $1.923 \mathrm{E} 2^{\mathrm{a}}$ & 8 & 0.001 \\
Likelihood Ratio & 12.774 & 8 & 0.120
\end{tabular}

$\mathrm{N}$ of Valid Cases

191

a. 9 cells $(60.0 \%)$ have expected count less than 5 . The minimum expected count is .01 .

The data in Table 4.14 above shows that out of the 112 respondents who reported to have undergone cervical cancer screening, $1(0.9 \%)$ had primary level of education, $9(8.0 \%)$ documented to have had secondary level of education, $58(51.8 \%)$ had attained college level of education and 44 (39.3\%) had acquired university level of education. Similarly, the highest proportion of those who had not had cervical screening was observed among college level of education where $42(53.2 \%)$ of the total who indicated they had not been screened for cervical cancer.

Additionally, Table 4.15 above show that at $95 \%$ confidence interval; a chi square test result of 1.923, and a p value of 0.001 , which is less than the expected 0.05 , demonstrates a statistically significant association between level of education and uptake of cervical cancer screening. The study therefore concluded that respondent's level of education significantly influences uptake of cervical cancer screening test among female health workers in in Kisumu County level four hospitals.

\subsubsection{The influence of participants marital status on uptake of cervical cancer screening}

Table 4.16 below shows the relationship between participant's marital status and uptake of cervical cancer screening as was collected during the study and analyzed using cross tabulation. Clearly, the data show that uptake of cervical cancer screening test is high among the married study population. Out of the 112 who had been screened for cervical cancer, $83(74.1 \%)$ reported to be married, $22(19.6 \%)$ were single $4(3.6 \%)$ were widowed and $3(2.7 \%)$ were separated. 
Table 4.16. Cross tabulation of marital status and uptake of screening

Cross tabulation of marital status and Cervical cancer screening $(\mathrm{N}=191)$

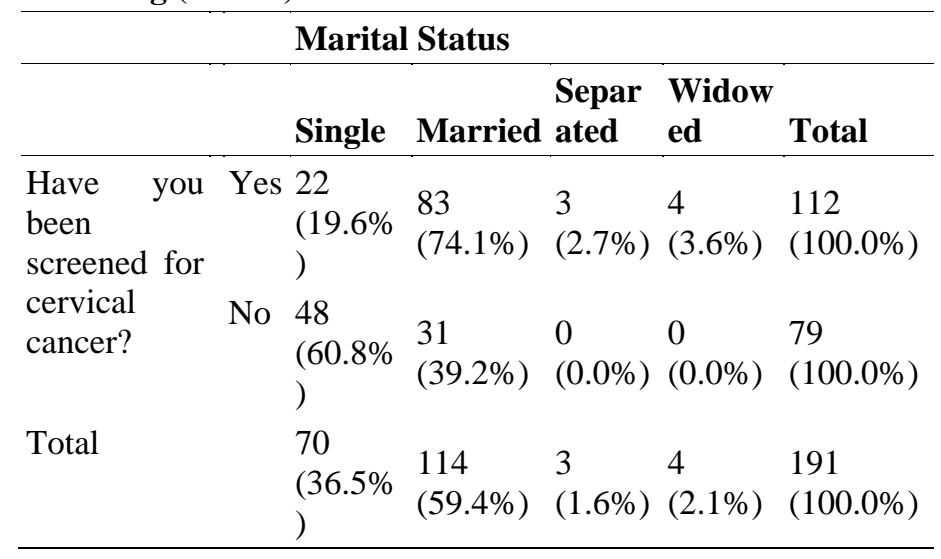

4.4.6. The influence of respondents parity on uptake of cervical cancer screening

Table 4.17 below illustrates respondent's parity as was elucidated during the study. A cross tabulation was done to determine the proportions of cervical cancer screening uptake based on parity.

Table 4.17. Cross tabulation of participant's parity and uptake of screening

\begin{tabular}{llllll}
\hline \multicolumn{6}{l}{ Participant's parity and cervical cancer screening uptake (N=191 } \\
\hline \multicolumn{5}{c}{ Respondents Parity } \\
\hline Have you been screened & Yes & $20(17.9 \%)$ & $85(75.9 \%)$ & $6(5.4 \%)$ & $112(100 \%)$ \\
for cervical cancer? & No & $37(46.8 \%)$ & $38(48.1 \%)$ & $4(5.1 \%)$ & $79(100 \%)$ \\
& Total & $\mathbf{5 7}(\mathbf{2 9 . 7 \% )}$ & $\mathbf{1 2 3}(\mathbf{6 4 . 1 \%})$ & $\mathbf{1 0}(\mathbf{5 . 2 \%})$ & $\mathbf{1 9 1}(\mathbf{1 0 0 \%})$ \\
\hline
\end{tabular}

The statistic highlighted in Table 4.17 above shows that out of the 112 questionnaires that were returned duly filled, 85 (75.9\%) had a parity of 1-4 children, 20 (17.9\%) were nulliparous, and $6(5.4 \%)$ had five-plus children. Notably, among those who reported not to have had a cervical cancer screening test, both nulliparous and women who reported 1-4 children contributed significantly at $37(46.8 \%)$ and $38(48.1 \%)$ respectively. This data shows that going by proportions, parity per se is not statistically associated to uptake of cervical cancer screening.

\subsection{Knowledge of cervical cancer and cervical cancer screening.}

Information is power, and it is believed that the more informed a person is, the more she is likely to make correct, upright and informed decision, especially relating to ones' own health. The researcher assessed this variable through the following measures: ever heard of cervical cancer screening, whether it is preventable, curable; risk factors to cervical cancer, methods of screening, and frequency of screening.

\subsubsection{The influence of participants' awareness of cervical cancer screening and its uptake.}

In this study, the researcher sought to establish the level of awareness of cervical cancer among female health worker through determining the proportion that had heard of cervical cancer screening, those who knew whether or not it is preventable, curable, and if it can be caught early in life. A Likert scale of analysis was employed to present quantitative data as shown in Figure 4.1 below. 


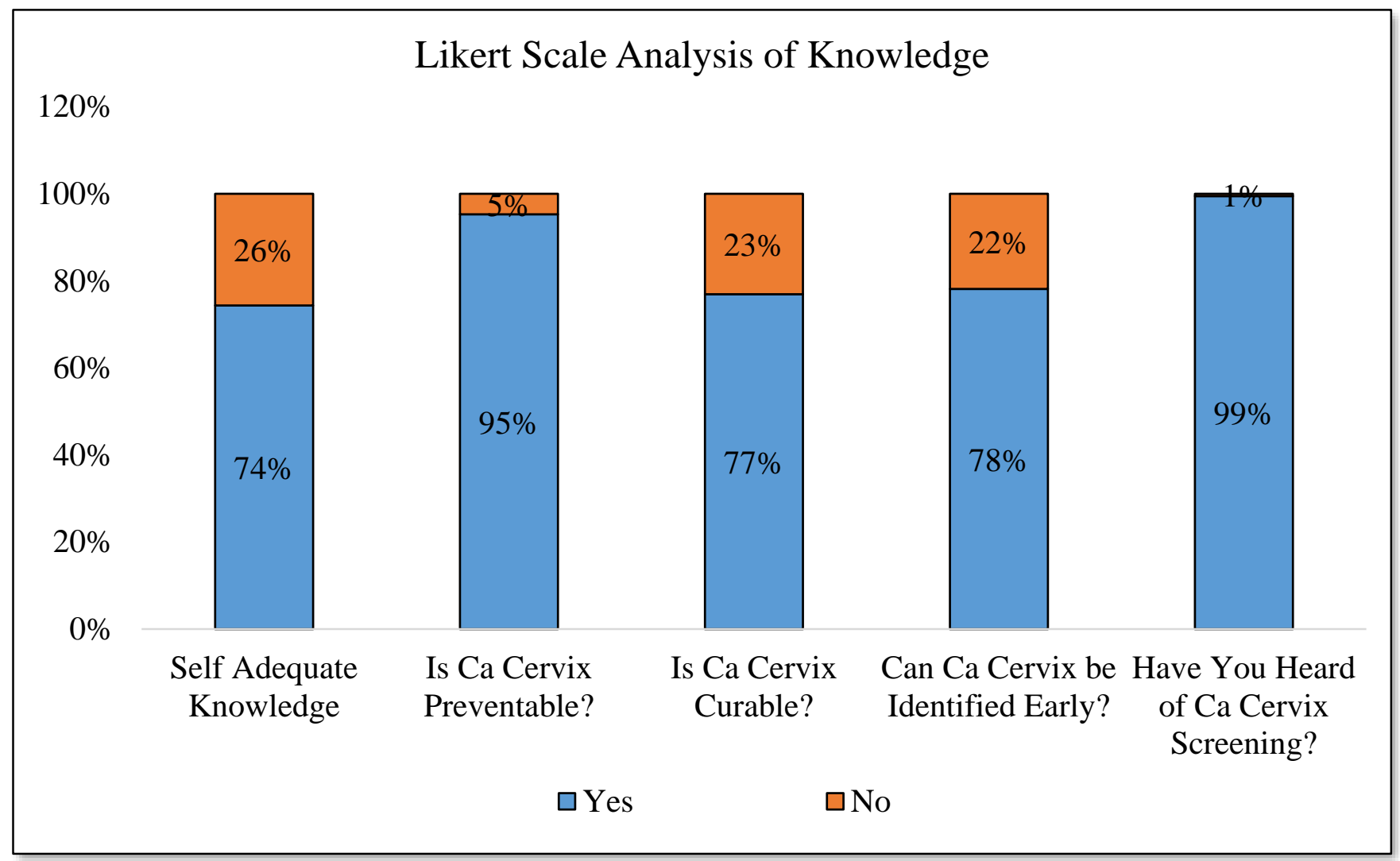

Figure 2 Likert scale of respondents' knowledge on cervical cancer

The statistic represented in Figure 4.1 above illustrates that out of the 191 questionnaires returned duly filled, 142 (74\%) of the participants considered themselves to have adequate knowledge of cervical cancer. The study found out that $182(95 \%)$ reported that cervical cancer is preventable, importantly 141 (74\%) documented that cervical cancer is curable with a further $147(77 \%)$ acknowledging that cervical cancer can be identified early. Ninety-nine percent of the respondents had heard of cervical cancer screening.

The median, mean and standard deviations were analyzed from the Likert scale to determine their variations with regard to knowledge being directly associated with uptake of cervical cancer screening where the population medians are equal. On a five-point Likert scale of analysis, all the populations posted similar measures of median and mean at 95.5 with a varied standard deviations ranging from -1.0 to -50.0 , this denotes that, since the median for the responses to questions with the same response is similar, there is a close association with desired outcome of cervical cancer screening uptake.

However, looking at standard deviation, when asked whether or not the respondent had heard of cervical cancer screening had a standard deviation measure of -1 , thus, this is the closest to the mean value. This study therefore concludes that awareness of cervical cancer is associated with uptake of its screening among female health workers in Kisumu County.

The influence of knowledge of risk factors on uptake of cervical cancer screening

The researcher set out to determine whether the study participants were aware of the risk factors to developing cervical cancer; this variable was assessed on the prism of female health workers identifying infection with human-immunodeficiency virus (HIV), smoking, practicing sexual intercourse with multiple partners, human papilloma virus infection, use of tampons and poor hygiene. A cross tabulation of participants responses and uptake was run as shown in Table 4.18 below.

Table 4.18. Cross tabulation of risk factors and screening uptake

\begin{tabular}{|c|c|c|c|c|}
\hline \multicolumn{5}{|c|}{$\begin{array}{l}\text { Cervical cancer risk factor*uptake of cervical cancer } \\
\text { screening cross tabulation }(\mathrm{N}=191)\end{array}$} \\
\hline \multirow[b]{2}{*}{$\begin{array}{l}\text { Risk factors to } \\
\text { cervical cancer }\end{array}$} & \multicolumn{4}{|c|}{ Cervical cancer screening uptake } \\
\hline & $\begin{array}{l}\text { Yes } \\
(\%)\end{array}$ & No $(\%)$ & $\begin{array}{l}\text { Chi sq. } \\
\text { test }\end{array}$ & p value \\
\hline HIV infection & $\begin{array}{l}83 \\
(61.0)\end{array}$ & $\begin{array}{l}53 \\
(39.0)\end{array}$ & 1.931 & 0.001 \\
\hline Smoking & $\begin{array}{l}35 \\
(61.4)\end{array}$ & $\begin{array}{l}22 \\
(38.6)\end{array}$ & 1.923 & 0.001 \\
\hline $\begin{array}{l}\text { Multiple } \\
\text { partners }\end{array}$ & $\begin{array}{l}92 \\
(57.1)\end{array}$ & $\begin{array}{l}69 \\
(42.9)\end{array}$ & 1.930 & 0.001 \\
\hline HPV infection & $\begin{array}{l}83 \\
(58.5)\end{array}$ & $\begin{array}{l}59 \\
(41.5)\end{array}$ & 1.920 & 0.001 \\
\hline IUDs & $\begin{array}{l}15 \\
(51.7)\end{array}$ & $\begin{array}{l}14 \\
(48.3)\end{array}$ & 1.927 & 0.001 \\
\hline Poor hygiene & $\begin{array}{l}25 \\
(52.1)\end{array}$ & $\begin{array}{l}23 \\
(47.9)\end{array}$ & 1.931 & 0.001 \\
\hline Use of tampons & $8(50.0)$ & $8(50.0)$ & 1.925 & 0.001 \\
\hline
\end{tabular}


The statistic in Table 4.18 above demonstrates that out of the 191 questionnaires returned duly filled, $136(71.2 \%)$ of the respondents identified HIV infection as a risk to developing cervical cancer, $161(84.3 \%)$ noted having multiple sex partners, while $142(74.3 \%)$ knew that infection with HPV would predispose an individual to developing cancer of the cervix.

Out of the 136 who identified HIV infection as a risk, 83 $(61.0 \%)$ had been screened for cervical cancer, among the 161 who mentioned multiple sex partners, $92(57.1 \%)$ had been screened, likewise, $83(58.5 \%)$ of the a42 who identified HPV infection as a risk had also been screened for cervical cancer. Infection with HIV, having multiple sex partners, and HPV infection were the commonest risk factors mentioned by majority of the respondents. A Chi sq. tests results of 1.931 at a $p$ value of 0.001 , which is less than the $p$ value of 0.05 , were found to be statistically significant. Therefore, this study confirmed that knowledge of risk factors to developing cervical cancer is significantly associated with uptake of cervical cancer screening test among female health workers in level four hospitals in Kisumu County.

Preponderance of the participants in the FGDs portrayed adequate knowledge of risk factors associated with cervical cancer. During the discussions, it was apparent that having multiple sexual partners, sexually transmitted infections and a family history would increase and individuals risk.

"I can say that having multiple sex partners could lead to cervical cancer because the men are known to carry the human papilloma virus which is known to cause cancer of the cervix" (FGD 4, participant 6, 25 years)

The influence of knowledge of the prevention measures of cervical cancer on the uptake of cervical cancer screening

To assess this variable, the researcher looked at knowledge of HPV vaccine, routine or regular screening, and safe sexual practices such as limitation of sexual partners, avoid smoking and correct and consistent use of condoms during sexual encounter. The participant's responses are shown in Table 4.19 below.

Table 4.19. Cross tabulation of prevention measures and screening uptake

\begin{tabular}{|c|c|c|c|c|}
\hline \multicolumn{5}{|c|}{$\begin{array}{l}\begin{array}{l}\text { Cervical cancer prevention measures*cervical cancer } \\
\text { screening uptake cross tabulation }(\mathrm{N}=191)\end{array} \\
\text { Cervical cancer screening }\end{array}$} \\
\hline \multirow[b]{2}{*}{$\begin{array}{l}\text { Prevention } \\
\text { measures }\end{array}$} & \multicolumn{4}{|c|}{ Cervical cancer screening } \\
\hline & Yes $(\%)$ & No $(\%)$ & $\begin{array}{l}\text { Chi } \\
\text { sq. } \\
\text { test }\end{array}$ & $\begin{array}{l}\text { p- } \\
\text { value }\end{array}$ \\
\hline HPV Vaccine & $58(60.4)$ & 38 (39.6) & 28.466 & 0.001 \\
\hline Routine screening & $91(58.7)$ & 64 (41.3) & 28.217 & 0.001 \\
\hline $\begin{array}{l}\text { Limit } \\
\text { partners }\end{array}$ & $52(49.5)$ & $53(50.5)$ & 34.872 & 0.001 \\
\hline Not smoking & $27(62.8)$ & $16(37.2)$ & 28.486 & 0.001 \\
\hline Use of conditions & $41(53.2)$ & $36(46.8)$ & 29.068 & 0.001 \\
\hline
\end{tabular}

The data in Table 4.19 above highlights that $155(81.2 \%)$ of the respondents were aware of routine cervical cancer screening as a measure of prevention, $105(55.0 \%)$ knew of limiting sexual partners, $96(50.1 \%)$ were aware of HPV vaccination, $77(40.3 \%)$ and $43(22.5 \%)$ knew of condom use during sexual intercourse and not smoking respectively.
Among the 155 who indicated routine cervical cancer screening, $91(58.7 \%)$ had been screened for cervical cancer, out of the 105 who knew having fewer sexual partners, $52(49.5 \%)$ had been screened for cervical cancer. Similarly, out of the 96 that mentioned HPV vaccination, only $58(60.4 \%)$ had been screened, while $27(62.5 \%)$ of the 43 who noted not smoking as a preventive measure had been screened for cervical cancer.

A chi sq. test of association run at 0.05 margin of error on all the measures: these resulting in a $p$ value of 0.001 , these were found to be statistically significant. The study thus concluded that knowledge of the prevention measures of cervical cancer is significantly associated with uptake of cervical cancer screening among female health workers in level four hospitals in Kisumu County.

Nearly all the FGD participants were aware that cervical cancer can be prevented through good hygiene, regular screening, not smoking or using alcohol, and where possible, avoiding multiple sexual partners.

"Preventing cancer of the cervix is possible since majority of us working in health sector understand the possible causes and risks" (FGD 2, participant 5, 42 years)

"I can say that cancer of the cervix is treatable especially if you get to diagnose it early, on the other hand, if it is diagnosed in advanced stage. It might not be cured" (FGD 1, participant 3, 25 years)

\subsubsection{The association between knowledge of cervical cancer symptoms and uptake of screening}

Table statistic presented in Table 4.20 below shows that preponderance of the respondent were aware of vaginal discharge, heavy vaginal bleeding and persistent lower abdominal pain as the most common symptoms of cervical cancer. One-hundred and thirty seven $(71.7 \%)$ not vaginal discharge, 127 (66.5\%) identified heavy vaginal bleeding, and $115(60.2 \%)$ identified lower abdominal pain

Successively, 78 (56.9\%) of the 137 who identified vaginal bleeding had been screened for cervical cancer, $76(59.8 \%)$ of the 127 who highlighted heavy vaginal bleeding had been screened for cervical cancer, while $73(63.5 \%)$ out of those who knew persistent lower abdominal pain as a symptom had been screened.

\section{Table 4.20. Cross tabulation of symptoms awareness and} screening uptake

\begin{tabular}{|c|c|c|c|c|}
\hline \multicolumn{5}{|c|}{ Knowledge of cervical cancer symptoms* Cervical cancer } \\
\hline \multirow[b]{2}{*}{$\begin{array}{l}\text { Symptoms of } \\
\text { cervical cancer }\end{array}$} & \multicolumn{4}{|c|}{ Cervical cancer screening } \\
\hline & Yes $(\%)$ & No (\%) & $\begin{array}{l}\text { Chi } \\
\text { sq. } \\
\text { test }\end{array}$ & $\begin{array}{l}P \\
\text { value }\end{array}$ \\
\hline $\begin{array}{l}\text { Bleeding between } \\
\text { periods }\end{array}$ & $37(50.7)$ & $36(49.3)$ & 1.951 & 0.001 \\
\hline $\begin{array}{l}\text { Persistent } \\
\text { abdominal pain }\end{array}$ & $73(63.5)$ & $42(36.5)$ & 1.948 & 0.001 \\
\hline Vaginal discharge & $78(56.9)$ & $59(43.1)$ & 1.926 & 0.001 \\
\hline $\begin{array}{l}\text { Heavy vaginal } \\
\text { discharge }\end{array}$ & $76(59.8)$ & $51(40.2)$ & 1.922 & 0.001 \\
\hline
\end{tabular}




\begin{tabular}{lcccc}
$\begin{array}{l}\text { Unexplained } \\
\text { weight loss }\end{array}$ & $44(53.7)$ & $38(46.3)$ & 1.935 & 0.001 \\
$\begin{array}{l}\text { Blood in stool or } \\
\text { urine }\end{array}$ & $10(45.5)$ & $12(54.5)$ & 1.938 & 0.001 \\
\hline
\end{tabular}

Chi sq. test of association was calculated, vaginal discharge had a result of 1.926, and heavy vaginal bleeding at a value of 1.922 , persistent lower abdominal pain had a chi sq. test result of 1.948 , and bleeding between periods scoring 1.951, all these indicators had a $p$ value of 0.001 at $95 \%$ confidence interval. These were statistically significant since they had a $\mathrm{p}$ value less than 0.05. This study therefore confirmed that the respondent's knowledge of symptoms of cervical cancer was statistically associated with uptake of cervical cancer screening among female health workers in Kisumu County level four hospitals.

During FGDs, most participants perceived themselves to have adequate knowledge of cervical cancer and its screening services. Vaginal bleeding and lower abdominal pain were predominantly mentioned symptoms for cervical cancer by participants.

"My grandmother developed abnormal vaginal bleeding way after menopause. This bleeding persisted prompting me to take her to a gynaecologist for checkup. She was diagnosed with late stage cervical cancer which we were told cannot be cured". (FGD 1, participant 2, 31 years)

4.6. Attitude towards cervical cancer screening on its uptake.

The researcher believed that the attitude of service providers towards a particular health intervention is detrimental or beneficial to its uptake by the general population. The general population perceive the health worker as custodian of skills and knowledge of benefits of any health intervention, which might otherwise result in better health outcomes. To this end, this variable was measured on whether or not the female health worker considered themselves to be at risk of cervical cancer; would accept to undergo cervical cancer screening; and where necessary, if they could pay for the service.

4.6.1. The influence of self-perception on the uptake of cervical cancer screening

The participant's response as to whether they considered themselves to be at risk of cervical cancer is illustrated in Table 4.21 below.

Table 4.21. Cross tabulation of perceived self-risk and uptake of screening

\begin{tabular}{|c|c|c|c|c|c|}
\hline \multicolumn{6}{|c|}{$\begin{array}{l}\text { Considering self to be } \\
\text { uptake }(N=191)\end{array}$} \\
\hline & & \multicolumn{3}{|c|}{ Cervical cancer screening } & \multirow[b]{2}{*}{$\begin{array}{l}\mathbf{P} \\
\text { value }\end{array}$} \\
\hline & & $\begin{array}{l}\text { Yes } \\
(\%)\end{array}$ & No $(\%)$ & $\begin{array}{l}\text { Chi } \\
\text { Sq. } \\
\text { Test }\end{array}$ & \\
\hline \multirow{3}{*}{$\begin{array}{l}\text { Consider } \\
\text { self to be at } \\
\text { risk of } \\
\text { cervical } \\
\text { cancer. }\end{array}$} & & $\begin{array}{l}79 \\
(65.8)\end{array}$ & $\begin{array}{l}41 \\
(34.2)\end{array}$ & 2.018 & 0.001 \\
\hline & No & $\begin{array}{l}18 \\
(39.1)\end{array}$ & $\begin{array}{l}28 \\
(60.9)\end{array}$ & & \\
\hline & $\begin{array}{l}\text { Don’t } \\
\text { Know }\end{array}$ & $\begin{array}{l}15 \\
(60.0)\end{array}$ & $\begin{array}{l}10 \\
(40.0)\end{array}$ & & \\
\hline
\end{tabular}

\begin{tabular}{lll} 
Total & 112 & 79 \\
& $(58.2)$ & $(41.1)$ \\
\hline
\end{tabular}

The data in Table 4.21 above shows that out of the 120 respondents who considered themselves to be at risk of cervical cancer, $79(65.8 \%)$ had been screened for cervical cancer, conversely, among the 46 who perceived themselves not be at risk, $28(60.9 \%)$ had not been screened for cervical cancer. A chi sq. test of association result at 2.018 with a $p$ value of 0.001 at $95 \%$ confidence interval was considered statistically significant. Therefore this study concluded that perception of oneself to be at risk was strongly associated with uptake of cervical cancer screening.

\subsubsection{The influence of willing to advocate for cervical cancer screening on uptake of CCS}

The respondents were asked if they could refer their clients for cervical cancer screening when they visit the hospital, Table 4.22 below illustrates the responses.

Table 4.22. Cross tabulation of willingness to advocate and uptake of screening

\begin{tabular}{|c|c|c|c|c|c|}
\hline \multicolumn{6}{|c|}{$\begin{array}{l}\text { Would you advocate for cervical cancer screening*cervical } \\
\text { cancer screening cross tabulation }(\mathrm{N}=191)\end{array}$} \\
\hline \multicolumn{6}{|c|}{ Cervical cancer screening } \\
\hline & & $\begin{array}{l}\text { Yes } \\
(\%)\end{array}$ & $\begin{array}{l}\text { No } \\
(\%)\end{array}$ & $\begin{array}{l}\text { Chi } \\
\text { sq. }\end{array}$ & $\begin{array}{l}\mathbf{P} \\
\text { value }\end{array}$ \\
\hline \multirow{3}{*}{$\begin{array}{lr}\text { Would } & \text { you } \\
\text { advocate } & \text { for } \\
\text { cervical cancer } \\
\text { screening? }\end{array}$} & Yes & $\begin{array}{l}108 \\
(59.3)\end{array}$ & $\begin{array}{l}74 \\
(40.7)\end{array}$ & 1.928 & 0.001 \\
\hline & No & $\begin{array}{l}4 \\
(44.4)\end{array}$ & $\begin{array}{l}5 \\
(55.6)\end{array}$ & & \\
\hline & Total & $\begin{array}{l}112 \\
(58.3)\end{array}$ & $\begin{array}{l}79 \\
(41.1)\end{array}$ & & \\
\hline
\end{tabular}

Data in Table 4.22 above illustrates that out of the 182 respondents who indicated that they would advocate for cervical cancer screening to their patients, $108(59.3 \%)$ of them had been screened, while 5 (55.6\%) of the nine who had reported they would not advocate screening for cancer of the cervix to their patients had not been screened. At a confidence interval of 95\%, a chi sq. test of association of 1.928 with a $p$ value of 0.001 is considered statistically significant. The study therefore concluded that willingness to advocate for cervical cancer screening to patients is strongly associated with uptake of cervical cancer screening among female health workers in level four hospitals of Kisumu County.

Among the FGD participants, 58.3\% had ever been screened for cervical cancer. That notwithstanding, majority of the participants expressed willingness to be screened in the future. The greatest facilitator of seeking cervical cancer screening among the study participants was experiencing signs and symptoms.

"I used to go for cervical cancer screening whenever I had heavy menstrual flow. Due to that, I have been screened at least three times" (FGD 1, participant 1, 45 years)

"What made me go for screening was because I used to experience severe abdominal pain followed by longer lasting menses" (FGD 4 , participant 3,22 years) 


\subsection{To assess the extent to which barriers to CCS influence its uptake among the respondents}

Potential barriers to uptake of cervical cancer by female health care workers was considered relevant by the researcher since this would explain why it is low in the first place. To asses this variable, the study looked at methods utilized and frequency of screening by those who reported to have screened, and understanding of the health worker on some of the reasons that would deter an individual from screening for cervical cancer.

\subsubsection{The influence of screening methods administered on the uptake of cervical cancer screening uptake}

Statistic in Table 4.23 below shows that out of the 112 respondents who had been screened for cervical cancer, 50 (44.6\%) were screened using VIA method, while $46(41.1 \%)$ had been screened through Pap smear and $16(14.3 \%)$ screened through VILI.

Table 4.23. Screening method administered

\begin{tabular}{lll}
\hline $\begin{array}{l}\text { Screening } \\
\text { Method }\end{array}$ & Frequency & Percentage \\
\hline VIA & 50 & 44.6 \\
Pap Smear & 46 & 41.1 \\
VILI & 16 & 14.3 \\
\hline
\end{tabular}

4.7.2. The influence of frequency of screening on the uptake of cervical cancer screening

Table 4.24 below describes those who had been screened for cervical cancer in terms of frequency. Preponderance of the respondents at $68(60.7 \%)$ had been screened at least once, 29 (25.9\%) had been screened twice, while 4 (3.4\%) had been screened five times or more.

Table 4.24. Participant's frequency of cervical cancer screening

\begin{tabular}{|c|c|c|}
\hline $\begin{array}{l}\text { Frequency of } \\
\text { screening }\end{array}$ & Frequency & Percentage \\
\hline Once & 68 & 60.7 \\
\hline Twice & 29 & 25.9 \\
\hline Thrice & 11 & 9.8 \\
\hline Five times or more & 4 & 3.4 \\
\hline
\end{tabular}

4.7.3. The influence of health system on uptake of cervical cancer screening

Health system inadequacy was one of cited reasons by respondents as a barrier to uptake of cervical cancer screening by respondents. These sentiments were similar to quantitative findings of this particular study. Lack of cervical cancer screening services in most public health facilities was echoed by all the FGDs as a significant barrier.

"Currently, only Jaramogi Oginga Odinga Teaching and Referral Hospital (JOOTRH) and Kisumu East County Hospital have the capacity to screen for cervical cancer" (FGD 2, participant 1,27 years)

\subsubsection{The influence of screening outcome fear on uptake of cervical cancer screening}

Notably, the most common barrier to accessing cervical cancer screening was fear of the screening outcomes. Screening positive for suspicious lesion was dreaded by most of the participants. This feeling was observed clearly during FGD sessions.

"Most women, especially we who work in health sector, are afraid of screening because of our knowledge on how the infected cervix look like, we don't want to be told that your cervix look that bad. So we would rather not screen, until you experience symptoms" (FGD 3, participant 6, 30 years)

\section{DISCUSSION}

\subsection{Introduction}

This chapter focusses on the deductions of the study on the backdrop of key study variables. In this study, the researcher sought to investigate the proportion of female health workers that had undergone cervical cancer screening; the extent to which knowledge of cervical cancer screening influences uptake among female health workers; how female health workers' attitude is associated with uptake of cervical cancer screening; and how do barriers to cervical cancer screening influence uptake.

\subsection{The proportion of female health workers who} have undergone cervical cancer screening.

Kenya Demographic Health Survey (KDHS 2014) established that demographic characteristics significantly influence health seeking behavior across all populations. To determine the proportion of those who had had cervical cancer screening, this study measured age, level of education, religion, occupation, marital status and parity, but solely focused on female health workers in level 4 hospitals in Kisumu County. Whereas this study established that $58.3 \%$ of the participants had undergone cervical cancer screening, compared to similar study in Usmanu Danfodiyo University Teaching and Referral Hospital, Nigeria which elucidated that $10 \%$ of the female health workers had underwent screening for cervical cancer (Oche et al. 2013), and $16 \%$ uptake among female health workers in Asikuma Odobome Barakwa District, Ghana (Juliet, 2019).

\subsubsection{The influence of respondents age on the uptake of cervical cancer screening}

Cervical cancer screening in Kenya is recommended to all women of reproductive age, and should be available in all level four hospitals. However, it is an opt-out service where the client has the chance to decline or accept the service whenever it is offered. In this study, 58.3\% of the participants had undergone cervical cancer screening, majority of them being within the ages of 25-32 years. This study also determined a statistical association between age and the uptake of cervical cancer screening. This can be attributed to the fact that the participants are working in the hospital settings, therefore have the opportunity to access the services easily. The findings of this study are in agreement with a study conducted in India on determinants of participation in cancer screening test which demonstrated that age was statistically significant in utilization of cervical cancer screening services (Nene and Jayant et al., 2007). 


\subsubsection{The influence of participants religion on the uptake of cervical cancer screening}

In this study, $58.1 \%$ of the participants who were Christians had undergone cervical cancer screening, with one hundred percent observed among the Muslim faithful. This can be attributed to both religion's teachings of good health and wellbeing (Shafqat K. A, 1997). Similar observations were recorded by Gonzalez and Gonzalez (2002) in Lagos, Nigeria.

\subsubsection{The influence of participant's cadre on uptake of cervical cancer screening.}

An individual's cadre in the health sector is presumably associated with economic prowess and their ability to enjoy considerable wage and better lifestyle, which in turn would subject them to practices that might put them at risk of acquiring or developing malignancies, such as cervical cancer. Likewise, those with economic engagements that do not sufficiently provide for their daily basic needs might find themselves engaging in activities that predispose them to cervical cancer, for instance, engaging in multiple sex partner relationships, or substance abuse. In this study, 55.5\% of the participants were nurses and clinical officers, these are the ones who would ordinarily be expected to provide cervical cancer screening in such hospitals. Consequently, $65.1 \%$ of them reported to have been screened for cervical cancer, denoting a high uptake compared to medical officers, community health workers, nutritionists or laboratory technologists.

The findings of this study however are contradicted by a study in Nigeria's University College Hospital, Ibadan (Oyeduni Sola Arulogun et al, 2012) which showed that junior nursing officers were four times less likely to be screened compared to their senior colleagues. Similarly, a study in Mulago Hospital, Uganda, determined that uptake is higher among doctors and paramedical staff compared to support staff (Nankya, 2018).

The high tendency of the clinical officers and nurses to have been screened can be attributed to their knowledge of cervical cancer, as this is part of their training in medical college. This study thus deduced that the health care workers cadre is significantly associated with uptake of cervical cancer screening.

\subsubsection{The influence of participants level of education on uptake of cervical cancer screening}

Education status is arguably reflective of level of knowledge one has acquired. The educated are expected to be more liberal and equipped with contemporary medical practices as opposed to those with sub-optimal education. Expectedly, the findings of this study determined that $91.2 \%$ of the participants had attained tertiary level of education and above. Correspondingly, this study also established that $58.3 \%$ of the participants had undergone cervical cancer screening. These findings therefore designated that the level of education does influence uptake of cervical cancer screening. A chi sq. test in this study revealed a statistically significant association between level of education and uptake of cervical cancer screening by the participants.

\subsubsection{The influence of participants marital status on the uptake of cervical cancer screening}

Married women have a greater propensity to keep to one sexual partner, hence fear of the unknown does not play. Moreover, in most cultural communities in Kenya, the married women would most of the time seek their spousal approval in matters of health interventions. This study found that uptake of cervical cancer screening was highest among married women at $74.1 \%$, compared to participants who reported to be single where $68.6 \%$ of them hand not been screened for cervical cancer. The findings of this study thus denotes that marital orientation significantly influences uptake of cervical cancer screening by female health workers. These findings corroborate those of a study conducted in India which determined that socio-demographic factors such as marital status are statistically significant in cervical cancer screening (Nene and Jayant et al., 2007).

\subsubsection{The influence of participant's parity on the uptake of cervical cancer screening.}

Presumably, parity is related to strenuous activities involving the cervical opening, thereby predisposing it to cancerous lesions including cervical cancer. This study established that uptake of cervical cancer screening is significantly practiced among females with 1-4 parity, $75.9 \%$ in this bracket reported to have screened. In contrast, only $35.1 \%$ of the nulliparous had been screened. This data demonstrates that parity directly influences uptake of cervical cancer screening, albeit minimal. These findings are in agreement with those found in Lagos, where $57.6 \%$ of the married women, and $64.7 \%$ with a parity of 2 plus had undergone cervical cancer screening at least once in their life (Gonzalez and Gonzalez, 2002).

\subsection{The extent to which knowledge on cervical cancer screening influences uptake}

It is questionably believed that the more a person is endowed with information, the more that person is likely to make informed choices. The KDHS (KNBS, 2014) highlighted that the people who have knowledge of available reproductive health services in public hospitals were more likely to make use of them.

\subsubsection{The influence of knowledge on cervical cancer screening on the uptake of screening}

This study determined that $74.1 \%$ of the participants were adequately informed on cervical cancer screening, with $99.5 \%$ reporting to have heard about cervical cancer screening. Knowledge was determined in terms of risk factors, signs and symptoms and prevention. When these variables were analyzed independently, $95.1 \%$ reported that it can be prevented or managed when identified early.

On a five point Likert scale of analysis, there were similar measures of central tendency, notably median and mean at 95.5, further denoting close association with desired outcome, in this case, uptake of cervical cancer screening. This was further elicited in the FGDs which had participant who had not only heard about 
cervical cancer screening, but had also been trained on how to conduct such screening. The statistic of this study therefore demonstrated that adequate knowledge significantly influences uptake of cervical cancer screening.

\subsubsection{The influence of knowledge of risk factors on the uptake of cervical cancer screening.}

This study established that $71.2 \%$ of the participants, with a further $74.3 \%$ of the participants associated infection with HIV and HPV as the leading predisposing factors to acquiring cervical cancer. Similarly, qualitative assessment through FGDs demonstrated that majority of the participants were well acquainted with HPV infection, multiple sex partners and HIV as the major risk factors. This study inferred that knowledge of risk factors significantly influences uptake of cervical cancer, this was demonstrated by the $61 . .0 \%$ of those who identified HIV infection, and $58.5 \%$ of those who identified HPV infection as a risk having been screened for cervical cancer. These findings are consistent with KDHS (KNBS, 2014) report which revealed that the now defunct Nyanza region had a high number of participants at $84.5 \%$ with adequate knowledge, not only of the existence of services, but also the risky practices that would predispose them.

A mirror study conducted in the Niger delta (Owoeye and Ibrahim, 2013) also revealed that $72.1 \%$ of its participants were aware of cervical cancer disease risk factors. In contrast, these findings were not consistent with a study carried out in rural Uganda which showed that awareness of risk factors significantly and willingness to screen did not directly translate to uptake as only $40.2 \%$ of the participants had been screened for cervical cancer despite demonstrating high levels of awareness (Ndejjo et al., 2016).

\subsubsection{The influence of knowledge on prevention on the uptake of cervical cancer screening}

Routine cervical cancer screening was predominant among the participants as a prevention measure. Limiting sexual partners and use of HPV vaccination were also highlighted by the participants. Whereas $81.2 \%$ of the participants supported routine cervical screening, only $58.3 \%$ of the participants had been screened for cervical cancer. These findings reinforce the need for increased campaign among female health workers given their detrimental role in provision of such services to the general population.

Additionally, given that only $50.1 \%$ of the participants knew that HPV vaccine could help prevent against cervical cancer, this knowledge gap is suicidal and hampers efforts by programmes promoting uptake of HPV vaccine among women, especially those in early years of puberty. Health care workers need regular sensitization and continuous medical knowledge development on HPV vaccine. These findings are in agreement with a study conducted in Jordan (Obeidat B, Amarin Z and Alzaghal L, 2012) which showed that $26 \%$ of the participants were not aware of the existence of a vaccine to prevent against cervical cancer.

\subsubsection{The influence of knowledge of symptoms on the uptake of cervical cancer screening}

Experiencing signs and symptoms, notably vaginal bleeding and persistent lower abdominal pain, were found to be the major facilitators for cervical cancer screening. Fifty-nine percent of participants who had experienced vaginal bleeding had been screened for cervical cancer. Participants from the FGDs also indicated that what prompted those who had been screened to seek the service were the symptoms they were having at the time. Undoubtedly, vaginal bleeding and persistent lower abdominal pain directly influence uptake of cervical cancer screening among health workers. These findings are similar to a study in rural Uganda which associated screening for cervical cancer to participants who had experienced signs and symptoms (Ndejjo et al., 2016).

\subsection{Attitude of female health workers and uptake of cervical cancer screening}

Health care workers present the face to access health services in any institution. They would sometimes subconsciously affect uptake of the services that they are required to promote. Their presentation of the service in question, and interaction with patients would go a long way in dictating whether or not they would advocate for it.

\subsubsection{The influence of self-risk perception on the uptake of cervical cancer screening}

This study had $68.2 \%$ of its participants considering themselves to be at risk of developing cervical cancer. However, only $65.8 \%$ had been screened for cervical cancer. Perception of self-risk is statistically associated with uptake of cervical cancer screening, albeit at a low scale. This finding was further echoed by FGDs participants among whom had gone for screening were compelled to do so because of them being at risk. Similar findings were recorded by Ndejjo and Kiguli (2017) in Uganda who narrated that awareness of some cervical cancer risk factors was high and most participants perceived themselves to be at risk.

Despite perceiving oneself to be at risk, $24 \%$ of the participants in this study had not undergone cervical cancer screening, they however expressed willingness to screen in the future. They equally stated that they would not be hesitant to advocate for, and refer clients for cervical cancer screening. This study therefore deduced that female health workers possess a positive attitude towards screening for cervical cancer. However, like the general population, they also need constant reminders and continued sensitizations, encouragements to undertake cervical cancer screening.

\subsection{Perceived barriers to cervical cancer screening influence uptake of screening}

This study elicited various possible barriers affecting uptake of cervical cancer screening. The screening procedure employed was found to be significant in determining uptake. In this study, $44.6 \%$ of the participants had been screened through VIA, while $41.1 \%$ had been screened through Pap smear. The FGDs determined that limited access to screening services was a 
major hindrance. This was because most public hospitals lack the capacity to routinely offer the service, thereby making it difficult for most women to have the screening. This coupled with the fear of the test outcome, made most women to only seek cervical cancer screening only when they experience symptoms such as persistent vaginal bleeding or lower abdominal pain.

These findings were found to be similar to a study conducted in sub-Saharan Africa by Lim and Ojo (2017) who described fear of the unknown as the major hindering factor to cervical cancer screening. In Uganda, limited health system capacity, potential consequences of integration where women are turned off, and fear of unknown as concerns to uptake of cervical cancer screening (Kumakech et al., 2014).

\section{CONCLUSION AND RECOMMENDATION}

\subsection{Introduction}

This chapter discusses conclusions and recommendations derived from this study. The conclusions are derived from findings of this study.

\subsection{Proportion of female health workers who had undergone cervical cancer screening}

In as much as more than half of the participants in this study had undergone cervical cancer screening, it is evident that a significant proportion of female health workers have equally not had screening for cervical cancer. This phenomena is alarming, arguably so because the health workers are expected to be the frontiers in utilization of health interventions aimed at improving health outcomes, more so, since they are educated on benefits of such interventions. The need for female health workers to take up this before they can even offer it to the general population cannot be understated.

\subsection{Knowledge of cervical cancer and screening among female health workers}

Knowledge about cervical cancer in realms of causes, signs and symptoms, risk factors, prevention measures and screening methods were well known to the participants. Nonetheless, nearly half of the participants had not been screened for cervical cancer. Those who had been screened, however, demonstrated good knowledge of cervical cancer. Deductively, the study participants believed that one would seek screening services when they perceived themselves to be at risk, or were experiencing symptoms. Programmes advocating for cervical cancer screening in women of reproductive age should consider having more female in their campaigns.

\subsection{Attitude of female health workers towards cervical cancer screening}

The study participants had a positive attitude towards cervical cancer screening. This was demonstrated by the willingness to have one screened for cervical cancer in the future. Furthermore, most of the study participants indicated that they would be willing to refer clients for cervical cancer screening. This study described how those participants who had undergone cervical cancer screening expressed positive attitude towards the service. Screening for cervical cancer is an important reproductive health intervention that need to be treated with the weight and attention it deserves. Cervical cancer being one of the leading causes of mortality among women, female health workers need to be assisted where possible so that they can take a leading role in not only provision of the service, but also being positive role models. A product is as good as the proprietor has tested it before sale to the general population

\subsection{Barriers to uptake of cervical cancer screening among female health workers}

Screening for cancer of the cervix by women in reproductive age is the gate pass to early detection and prompt initiation on therapy. The most common barriers to cervical cancer screening reportedly were health system related; the participants indicated that since fewer hospitals had the capacity to provide the service, this made it difficult for them to access it. Furthermore, some of the participants reiterated that they feared the outcome of the screening test. Quantitative data showed religious interference with seeking cervical cancer screening services. These notwithstanding, it is clear that all the participants are ready to undergo screening should the opportunity present itself.

\subsection{Recommendations}

\subsubsection{Recommendations for policy implications}

I. It is evident from this study that despite high level of awareness of cervical cancer screening, utilization remain sub optimal, thus, this study recommend that there is need for female health workers be actively involved in cancer screening service delivery units, this might dispel their fear and uncertainties associated with screening

II. Strategies that encourage utilization among the health professionals is highly advocated for such as cervical screening programs by both Ministry of Health and its development partners

III. Level four and below public hospitals personnel should be capacity built with required skills and expertise to provide cervical cancer screening services.

Further qualitative studies are recommended to be conducted in female health workers in level facilities

\section{REFERENCES}

[1] ACS. (2017, January o6). American Cancer Society. Retrieved from American Cancer Society website: https://www.cancer.org

[2] Arossi Silvina, Elena Matos, Nicolas Zengarini, Berta Roth and Rengaswamy Sankaranayananan. (2007). The soci-economic impact of cervical cancer on patients and their families in Argentina, and its influence on radiotherapy compliance. Science Direct. Gynaecology Oncology, 335-340.

[3] Asuzu, Unegbu and Akin . (2012). Knowledge, Attitude and Behaviour of the University of Ibadan Women Towards Cancer of the Cervix and its Prevention. European Journal of Cancer Care, 1010-1015.

[4] Bhagwan N, Kasturi J, Silvana A, Surendra S, Atul B and Sanjay H. (2007, October 14). Determinants of women's participation in cervical cancer screening trial in Maharastra, India. Bulletin of World Health organization, pp. 264-272.

[5] Bruni L, Barrionuevo Rossas L, Alberto G, Serrano B, Mena M, Gomez D and M. J,. (2016). Human Papilloma virus and Related Diseases Report. Baercelona. Spain: NHS

[6] Charmaz Kathy. (2006). Constructing Grounded Theory: A practical guide through qualitative analysis. London: Sage Publications. 
[7] Chemtai Mungo, C. C. (2013). Prevalence, characteristics and outcomes of HIV positive women diagnosed with invasive cancer of the cervix in Kenya. International Journal of Gynaecology, 231-235.

[8] Cunningham M. S, Skratis E, Fitzpatrick R, Jindal P, Oneko O, Yeates K, Booth C, M. Carpenter J and Aronson K, J. (2015). Cervical cancer screening and HPV vaccine acceptability among rural and urban women in Kilimanjaro region, Tanzania. BMJ Open Acess.

[9] Denise F. Polit, and Cheryl T. Becker. (2010). Essentials of Nursing Research: Appraising Evidence for Nursing Practice. New York: Lippincot Williams and Wilkins.

[10] Edmonds, K. D. (2007). Dewhurst's Textbook of Obstetrics and Gynaecology (tth ed.). London, Inited Kingdom: Blackwell Publishers.

[11] EO Jagun, A. E. (2016). Uptake of cervical cancer screening services among female medical practitioners in Ogun State, South West Nigeria. Annals of Health Research, 2(2), 79-79.

[12] Everlyne N Morema, Atieli Harrysone, Onyango R.O, Omondi J.H,. (2014). Determinants of cervical cancer screening services uptake among 18-49 years old seeking services at Jaramogi Oginga Odinga Teaching and Refferal Hospital. PMC, 335.

[13] Gichinga P, Estambale P, Bwayo J, Rogo K, Ojwang' S, opiyo A and T. N. (2003). Knowledge and practice of about cervical cancer and pap smear testing among patients at Kenyatta National Hospital, Nairobi. International journal of Gynaecology, 827-833.

[14] Hoque M, Hoque E and Kader S. (2008). Evaluation of Cervical cancer Screening Program in Rural Community of South Africa. East Africa Journal of public Health, 48-56.

[15] Iffemeluma et al. (2019). Cervical Cancer Screening: Assessmemt of Perception and Utilization of Services among Health Workers in Low Resource Setting. Interntional Journal of Reproductive Medicine.

[16] Jagun E. O, Ekundayo A E, O. J.. (2016). Uptake of cervical cancer screening services among female medical practitioners in Ogun state, south west Nigeria. Annals of Health Research, 79.

[17] Javed H and Risvi N. (2006). Womens Health in Developing Coutries: best practice and reseach in clinical obstetrics and gynaecology. Elsevier, 11-13.

[18] Juliet, N. (2019, July 7). Knowledge and screening practices on cervical cancer among health workers in Asikuma Odoben Brakwa District, Ghana. Retrieved from University of Ghana Digital Collections, UGSpace: http://ugspace.ug.edu.gh/handle/123456789/33500

[19] Jyoshma Preema Dsouza, Stephan Van den Broucke, Sanjay Pattanshetty and William Dhoore. (2020, August 21). Exploring the Barriers to Cervical Cancer Screening Through the lens of Implementers and Beneficiaries of the National Screening Program: A Multi-Contextual Study. Asian Pacific Journal of Cancer Prevention, 2209-2215. doi:10.31557/APJCP.2020.21.8.2209

[20] Kabir M, Iliyasuz Z, Abubakar I. S and M, S. . (2005). Awareness and practice of cervical cancer among female health professionals in Murtala Mohammed Specialist Hospital, Kano. Niger post grad medical journal, 179182.

[21] KCNS. (2017). Kenya Cancer Control Strategy 2011 - 2016. Nairobi: Kenya Cancer and National Strategy.

[22] KNBS. (2014). Kenya Demographic Health Survey. Nairobi: Kenya National Bureau of Statistics.

[23] Kumakech E., Anderson S and Wabinga H et al. (2014). Integration of HIV and Cervical Cancer Screening Perceptions of Healthcare Providers and policy Makers in Uganda. BMC Public Health, 1(14). doi:10.1186/14712458-14-810

[24] Lim J.N. and Ojo A. (2017). Barriers to Utilization of Cervical Cancer Screening in sub-Saharan Africa: a systematic review. European Journal of Cancer Care, 1(26).

[25] Lippincott Williams and Wilkins. (2007). Succesful Introduction of Routine opt-out HIV Testing in Antenatal Care in Botswana. J Acquir Immune Defic Syndr., $102-107$.

[26] Lyimo F S and Beran T N. (2012). Demographic, Knowledge, Attitude and Accessibility Factors Associated with Uptake of Cervical Cancer Screening Among Women in Rural Districts of Tanzania: a three policy implications. BMC, 22.

[27] Ministry of Health. (2015). Kisumu County Health Profile. Ksiumu: MOH.

[28] MOH. (2013). National Guidelines for Cancer Management in Kenya. Nairobi: Ministry Health. Kenya.
[29] Mugenda M and Mugenda G. (1999). Research Methods: Quantitative and Qualitative Approaches. Nairobi, Kenya: Act Press.

[30] Mugenda, Olive M. and Mugenda Abel G. (2003). Research Methods: Quantitative and Qualitative Approaches. Nairobi, Kenya: ACTS Press.

[31] Nankya, E. (2018, November). School of Nursing and Midwifery, Mulago Hospital. Uganda. Retrieved from School of Nursing and Midwifery: http://dspace.ciu.ac.ug/xmlui/handle/123456789/1304

[32] NASCOP. (2014). National AIDS and STI Control Prpgramme (NASCOP), Kenya. Kenya AIDS Indicator Survey 2012: Final Report. Nairobi: NASCOP

[33] Ndejjo R and Kiguli J. (2017). Knowledge, Facilitators and Barriers to Cervical Cancer Screening Among Women in Uganda: a qualitative study. BMJ Open Acess, 7. doi:10.1136/bmjopen-2017-016282

[34] Ndejjo, R Mukama. and Musabyimana A et al. (2016). Uptake of Cervical Cancer Screening and Associated Factors Among Women in Rural Uganda: a cross sectional study. PLoS one, 1. doi:10:1371/journal.pone.0149696

[35] Nene B, Jayant K, Arrossi S, Shasti S, Budukh A, Hingimire S, Sankaranarayan R. (2007). Determinants of women's participation in cervical cancer screening trial. Maharashtra. India. Bulletin of the World Health Organization, pp. 264-272.

[36] Ntekim. (2012). Cervical Cancer in sub-Saharan Africa; in Rajkumar R (ed). Tpoics on Cervical Cancer with an Advocacy for Prevention. Open Access, pp. 51-75.

[37] Obeidat B, Amarin Z and Alzaghal L. (2012). Awareness, Practice and Attitude to Cervical Pap Smear Among Female Health Workers in Jordan. European Journal of Cancer Care, 3(21), 372-376.

[38] Oche M. O, K. A. (2013). Cancer of the cervix and cervical screening: Current knowledge, attitude and practices of female health workers in Sokoto, Nigeria. International Journal of Medicine and Medical Sciences, 184-190. doi:10.5897/IJMMS2013.0886

[39] Owoeye I and Ibrahim I. (2013). Knowledge and Attitude Towards Cervical Cancer Screening Among Female Students and Staff in a Tertiary Institution in Niger Delta. International Journal of Medicine and Biomedical Research, 2(1), 48-56.

[40] Oyeduni Sola Arulogun et al. (2012). Perception and utilization of cervical cancer screening services among female nurses in University College Hospital, Ibadan. Nigeria. Pan African Medical Journal.

[41] Rawlance Ndejjo, Trasias Mukama, Angele Musabyimana and David Musoke. (2016). Uptake of Cervical Cancer Screening and Associated Factors Among Women in Rural Uganda: A Cross Sectional Study. PLoS One, Journal.

[42] Shafqat K. A, A. (1997). Promotive and Prophylactic Healtrh Aspects Based on Islamic Teachings. Bulletin of the Indian Institute of History of Medicine, 27, pp. 147-153.

[43] Shari L. Dworkin. . (2012). Sample Size Policy for Qualitative Studies Using In-depth Interventions. Archives of Sexual Behaviour, 41, 1319-1320.

[44] Staci L. Sudenga, Anne F. Rositch and Walter A. Otieno. (2013). Knowledge, attitude and perceived risks of cervical cancer among Kenyan women. International Journal of Gynaecologist Cancer, 895-899.

[45] Twaha Mutyaba and Francis Mmiro. (2011). Knowledge, Attitude and Practice on Cervical Cancer Screening Among the Medical Workers of Mulago Hospital, Uganda. BMC Medical Education, 13.

[46] Ugwu E. O, Obi S. N, Ezechukwu P. C, Okafor I. I,. (2013). Acceptatability of human pappilloma virus vaccine and cervical cancer screening among female health care workers in Enugu, South east Nigeria. BMC public health, 25.

[47] Urasa M. (2011). Knowledge of cervical cancer and screening practices of nurses at a regional hospital in Tanzania. African Health Science.

[48] WHO. (2014). Comprehensive Cervical Cancer Control: A guide to essential practice. Geneva, Switzerland: World Health Organization.

\section{AUTHORS}

First Author - Judy Ntabo - Bachelor of Science in Nursing, Master of Public Health candidate, Jomo Kenyatta University of Agriculture and Technology (JKUAT), ntabojudy@gmail.com 
Second Author - Bachelors of Science in Pharmacology, Masters in Community health Development, Jomo Kenyatta University of Agriculture and Technology

(JKUAT),dmokaya@jkuat.ac.ke

Third Author - Caroline Musita - Bachelors of Science in Nutrition, Masters in Community health Development, Jomo
Kenyatta University of Agriculture and Technology (JKUAT),cmusita@jkuat.ac.ke

Correspondence Author - Judy Ntabo, ntabojudy@ gmail.com, Tel: +254721845425 . 